OPEN ACCESS

Nickel, Manganese, and Cobalt Dissolution from Ni-Rich NMC and Their Effects on NMC622-Graphite Cells

To cite this article: Roland Jung et al 2019 J. Electrochem. Soc. 166 A378

View the article online for updates and enhancements. 


\title{
Nickel, Manganese, and Cobalt Dissolution from Ni-Rich NMC and Their Effects on NMC622-Graphite Cells
}

\author{
Roland Jung, ${ }^{1,2, \mathrm{z}}$ Fabian Linsenmann, ${ }^{1}$ Rowena Thomas, ${ }^{3}$ Johannes Wandt, ${ }^{1}$ \\ Sophie Solchenbach, $\odot 1, *$ Filippo Maglia, ${ }^{2}$ Christoph Stinner, ${ }^{2}$ Moniek Tromp, ${ }^{4}$ \\ and Hubert A. Gasteiger ${ }^{1, * *}$ \\ ${ }^{1}$ Chair of Technical Electrochemistry, Department of Chemistry and Catalysis Research Center, Technische Universität \\ München, Garching, Germany \\ ${ }^{2}$ BMW Group, Munich, Germany \\ ${ }^{3}$ Institute for Catalyst Characterization, Technische Universität München, Garching, Germany \\ ${ }^{4}$ Van't Hoff Institute for Molecular Sciences, University of Amsterdam, Amsterdam, Netherlands
}

\begin{abstract}
Transition metal dissolution from the cathode active material and its deposition on the anode causes significant cell aging, studied most intensively for manganese. Owing to their higher specific energy, the current focus is shifting towards nickel-rich layered $\mathrm{LiNi}_{\mathrm{x}} \mathrm{Mn}_{\mathrm{y}} \mathrm{Co}_{\mathrm{z}} \mathrm{O}_{2}(\mathrm{NMC}, \mathrm{x}+\mathrm{y}+\mathrm{z}=1$ ) with $\mathrm{x}>0.5$, so that the effect of $\mathrm{Ni}$ dissolution on cell degradation needs to be understood. This study investigates the dissolution of transition metals from a NMC622 cathode and their subsequent deposition on a graphite anode using operando X-ray absorption spectroscopy. We show that in NMC622-graphite cells transition metals dissolve nearly stoichiometrically at potentials $>4.6 \mathrm{~V}$, highlighting the significance of investigating Ni dissolution/deposition. Using NMC622graphite full-cells with electrolyte containing the bis(trifluoromethane)sulfonimide (TFSI) salts of either Ni, Mn, or Co, we compare the detrimental impact of these metals on cell performance. Using in-situ and ex-situ XRD, we show that the aging mechanism induced by all three metals is the loss of cycleable lithium in the solid electrolyte interface (SEI) of the graphite. This loss is larger in magnitude when $\mathrm{Mn}$ is present in the electrolyte compared to $\mathrm{Ni}$ and $\mathrm{Co}$, which we ascribe to a higher activity of deposited Mn towards SEI decomposition in comparison to $\mathrm{Ni}$ and $\mathrm{Co}$.

(C) The Author(s) 2019. Published by ECS. This is an open access article distributed under the terms of the Creative Commons Attribution Non-Commercial No Derivatives 4.0 License (CC BY-NC-ND, http://creativecommons.org/licenses/by-nc-nd/4.0/), which permits non-commercial reuse, distribution, and reproduction in any medium, provided the original work is not changed in any way and is properly cited. For permission for commercial reuse, please email: oa @electrochem.org. [DOI: 10.1149/2.1151902jes]
\end{abstract}

(cc) BY-NC-ND

Manuscript submitted November 2, 2018; revised manuscript received December 28, 2018. Published February 1, 2019.

Li-ion batteries are a key technology on the way to electromobility and have already proven to be capable as power supply for electric vehicles (EVs) or hybrid electric vehicles (HEVs). So far, the market of EVs and HEVs is rather small compared to the overall vehicle market. Yet, a longer driving range achieved by improved specific energies as well as significantly reduced costs might enable penetration of the mass market. ${ }^{1,2}$ Among several potential cathode active materials (CAMs), layered lithium nickel manganese cobalt oxide $\left(\mathrm{LiNi}_{\mathrm{x}} \mathrm{Mn}_{\mathrm{y}} \mathrm{Co}_{\mathrm{z}} \mathrm{O}_{2}, \mathrm{NMC}\right.$, with $\left.\mathrm{x}+\mathrm{y}+\mathrm{z}=1\right)$ is one of the most promising classes of materials. ${ }^{3,4}$ While NMC111 is already widely used in EVs, the research focus is shifting to the so-called nickel-rich (Ni-rich) NMCs with $\mathrm{x}>0.5$, because with growing Nicontent more lithium can be extracted from the layered NMC structure for a given upper potential limit, resulting in improved specific energies. ${ }^{3,5-7}$

The dissolution of transition metals, in particular of manganese $(\mathrm{Mn})$, was first identified as a major aging mechanism in $\mathrm{LiMn}_{2} \mathrm{O}_{4}$ (LMO) spinel cathodes causing, severe capacity fading in fullcells. ${ }^{8-13}$ Later on, transition metal dissolution was also investigated for the layered NMC materials, showing that this phenomenon is not limited to LMO. ${ }^{14-18}$ The detrimental effect of transition metal dissolution can have two origins: i) simply a loss of CAM due to active material degradation in the course of transition metal dissolution into the electrolyte, and/or ii) subsequent deposition and accumulation of transition metals on the graphite anode. The former is of minor importance, as only rather small amounts of the overall transition metal amounts in the CAMs are dissolved. For example, Choi et al. soaked various CAMs in $\mathrm{LiPF}_{6}$ based electrolyte and determined the overall metal dissolution upon storage at $55^{\circ} \mathrm{C}$ for 7 days to amount to $0.9 \%$ for NMC $111 .^{18}$ Buchberger et al. found for NMC111-graphite cells an overall transition metal dissolution corresponding to $0.08 \%$ and $0.77 \%$ of the CAM when the cells were cycled

\footnotetext{
*Electrochemical Society Student Member.

**Electrochemical Society Fellow.

${ }^{\mathrm{z} E}$ E-mail: roland.jung@tum.de
}

at $25^{\circ} \mathrm{C}$ to 4.2 (300 cycles) and $4.6 \mathrm{~V}$ (235 cycles), respectively. ${ }^{14}$ In contrast, the deposition and accumulation of dissolved transition metals on the graphite anode was shown to induce irreversible side reactions, leading to ongoing SEI formation and electrolyte reduction, ultimately resulting in the loss of active lithium and in cell impedance growth. ${ }^{17,19-24}$ For instance, Pieczonka et al. reported significant $\mathrm{Ni}$ and $\mathrm{Mn}$ dissolution from $\mathrm{LiNi}_{0.5} \mathrm{Mn}_{1.5} \mathrm{O}_{4}$ (LNMO) and showed that LNMO-Li half-cells can be cycled with high capacity retention, so that the direct effect of CAM decomposition on capacity loss must be negligible; on the other hand, for LNMO-graphite full-cells with a lithium inventory limited by the lithium contained in the LNMO cathode, severe capacity fading was observed, which was attributed to the loss of active lithium caused by the deposited $\mathrm{Ni}$ and $\mathrm{Mn}$ on the graphite anode. ${ }^{23}$ Analogously, upon extended cycling of NMC111-graphite cells to $4.2 \mathrm{~V}$, Buchberger et al. also observed transition metal dissolution and deposition on the graphite anode, accompanied by a loss of active lithium. After reassembling the NMC electrode in a NMC-Li cell, the full capacity of the NMC electrode was recovered, proving that the cathode active material stayed intact. $^{14}$

In the literature, the most frequently investigated transition metal is $\mathrm{Mn}$, despite the fact that NMCs increasingly richer in $\mathrm{Ni}$ are being implemented. Therefore, the effect of $\mathrm{Ni}$ in comparison to Mn has to be understood in order to project the impact of transition metal dissolution on the lifetime of batteries based on Ni-rich NMCs or on other Ni-rich materials like NCA $\left(\mathrm{LiNi}_{0.8} \mathrm{Co}_{0.15} \mathrm{Al}_{0.05} \mathrm{O}_{2}\right)$. Herein, we report the transition metal dissolution and subsequent deposition on the graphite anode from a NMC622-graphite cell using operando $\mathrm{X}$-ray absorption spectroscopy (XAS). Furthermore, we present a comparative study of the detrimental effect of deliberately added $\mathrm{Ni}$, $\mathrm{Mn}$, and Co ions on the cycling stability of NMC622-graphite cells. We will investigate the aging mechanism caused by the different metal ions in these accelerated cell aging tests. In view of previous literature reports and our here presented results, we will evaluate the possible mechanisms causing the faster cell degradation induced by transition metal deposits on the anode. 


\section{Experimental}

Electrode preparation.- $\mathrm{LiNi}_{0.6} \mathrm{Mn}_{0.2} \mathrm{Co}_{0.2} \mathrm{O}_{2}$ (NMC622, Umicore, Belgium) electrodes were prepared by dispersing $91.5 \%$ wt of the active material particles, $4.4 \%$ wt conductive carbon (Super C65, Timcal, Switzerland), and $4.1 \%$ wt polyvinylidene fluoride binder (PVDF, Kynar HSV 900, Arkema, France) in N-methylpyrrolidone (NMP, anhydrous, $99.5 \%$, Sigma-Aldrich). The slurry was mixed in a planetary mixer (Thinky, USA) at $2000 \mathrm{rpm}$ for $2 \times 5$ minutes. In between the two runs, the slurry was ultrasonicated for 10 minutes in an ultrasonic bath. The resulting ink was spread onto aluminum foil (thickness $18 \mu \mathrm{m}$, MTI Corporation, USA) using a gap bar coater (RK PrintCoat Instruments, UK). For the in-situ XRD measurement, the NMC cathode was prepared by coating the slurry through a mask $(110 \mu \mathrm{m}$ thick, with a $12 \mathrm{~mm}$ diameter hole) onto an aluminum foil (18 $\mu \mathrm{m}$ thickness, MTI Corporation, USA) with a diameter of $42 \mathrm{~mm}$, whereby the aluminum foil serves both as current collector and X-ray window.

Graphite electrodes were composed of $95.8 \%$ wt graphite (MAGD20, Hitachi), $1 \%_{\mathrm{wt}}$ Super C65 (Timcal, Switzerland), $1 \%_{\mathrm{wt}}$ sodium carboxymethylcellulose (Na-CMC, Dow Wolff Cellulosics), and $2.2 \%$ wt styrene-butadiene rubber (SBR, JSR Micro). For the slurry preparation, graphite, Super C65, and Na-CMC were dispersed in highly pure water $(18 \mathrm{M} \Omega \mathrm{cm}$, Merck Millipore, Germany) and mixed in a planetary mixer (Thinky, USA) at $2000 \mathrm{rpm}$ for 30 minutes. Subsequently, the slurry was ultrasonicated for 10 minutes in an ultrasonic bath. SBR was added to the slurry and mixed at $500 \mathrm{rpm}$ for $2 \mathrm{~min}-$ utes. The ink was coated onto copper foil (thickness $12 \mu \mathrm{m}$, MTI Corporation, USA) using a gap bar coater (RK PrintCoat Instruments, UK).

Electrodes containing only conductive carbon (Super C65, Timcal, Switzerland) had a composition of $50 \%$ wt Super C65 and $50 \%$ wt polyvinylidene fluoride binder (PVDF, Kynar HSV 900, Arkema, France). The solids were dispersed in N-methylpyrrolidone (NMP, anhydrous, $99.5 \%$, Sigma-Aldrich), mixed in a planetary mixer (Thinky, USA) at $2000 \mathrm{rpm}$ for 30 minutes, and then coated onto copper foil (thickness $12 \mu \mathrm{m}$, MTI Corporation, USA) or stainless steel mesh (316 grade, $26 \mu \mathrm{m}$ aperture, $25 \mu \mathrm{m}$ wire diameter, The Mesh Company, UK) using a gap bar coater (RK PrintCoat Instruments, UK).

All coatings were dried at $50^{\circ} \mathrm{C}$ in air, electrodes were punched out, dried overnight at $120^{\circ} \mathrm{C}$ under dynamic vacuum in a glass oven (drying oven 585, Büchi, Switzerland) and transferred into a glovebox $\left(\mathrm{O}_{2}\right.$ and $\mathrm{H}_{2} \mathrm{O}<0.1 \mathrm{ppm}$, MBraun, Germany) without exposure to ambient air. Electrodes were not calendered.

Operando X-ray absorption spectroscopy.-Operando X-ray absorption spectroscopy was used to measure the dissolution of transition metals from NMC622 and their subsequent deposition on a graphite electrode. The X-ray absorption spectra were measured at the ESRF synchrotron (BM23 beamline), France. The acquisition time for each spectrum presented in this work was approximately 9 minutes. The synchrotron was operating in $7 / 8+1$ top up mode. A sagittaly focusing double crystal monochromator consisting of two Si 111 crystals was used to select the incoming energy and the beam was focused using Si coated mirrors; then, the beam was cut with slits to achieve a beam size of $140 \mu \mathrm{m}$ in the horizontal dimension (i.e., along the thickness of the graphite electrode) and approximately $1000 \mu \mathrm{m}$ in the vertical dimension (i.e., along the width of the graphite electrode). With the incident angle of $45^{\circ}$, this yields a probing area of $198 \times$ $1000 \mu \mathrm{m}$. These dimensions allow focusing the beam exclusively on the graphite electrode, which had a dimension of $226 \times 10000 \mu \mathrm{m}$ (thickness $\mathrm{x}$ width). As we are using hard X-rays in the energy range of 6-8 $\mathrm{keV}$ the probing depth of the XAS method is rather high on the order of $\sim 100 \mu \mathrm{m}$ making the method bulk sensitive. The cells were assembled as described below, and measured in fluorescence mode with an energy selective 13-element Ge detector to collect the photons. Photon energies were calibrated using the first peak in the first derivative of the pure metal foils, which were measured in fluorescence before and after the operando studies; background corrections of the spectra were carried out using the IFEFFIT software package. ${ }^{25,26}$
NMC622-graphite cells were assembled using the XAS cell design described by Gorlin et al. ${ }^{27}$ Both electrodes were cut as squares with a side length of $10 \mathrm{~mm}$ and had an NMC loading of $25.4 \mathrm{mg}_{\mathrm{NMC}} / \mathrm{cm}^{2}$ $\left(5.07 \mathrm{mAh} / \mathrm{cm}^{2}\right.$, thickness: $\left.92 \mu \mathrm{m}\right)$ and a graphite loading of $20.1 \mathrm{mg}_{\text {graphite }} / \mathrm{cm}^{2}\left(7.12 \mathrm{mAh} / \mathrm{cm}^{2}\right.$, thickness: $\left.226 \mu \mathrm{m}\right)$. In between the electrodes, two glassfiber separators $(250 \mu \mathrm{m}$ uncompressed thickness, glass microfiber filter 691, VWR) and $300 \mu \mathrm{L}$ electrolyte $(1 \mathrm{M}$ $\mathrm{LiPF}_{6}$ in EC:EMC 3:7, BASF, Germany) were used. In analogy to the work by Wandt et al., ${ }^{15}$ the X-ray window consisted of an aluminized $12 \mu \mathrm{m}$ Kapton foil (aluminized side placed towards the cell exterior) and an additional $25 \mu \mathrm{m}$ Kapton foil on top of the aluminum layer in order to prevent mechanical damage to the thin aluminum layer. The X-ray beam was focused on the graphite electrode, making it possible to selectively measure the XAS spectra transition metal deposits within the anode. The operando cell was connected to a SP200 potentiostat (SP200, Biologic, France) and two charge/discharge cycles between cell voltages of 2.6 and $4.6 \mathrm{~V}$ were performed at a 0.5 C-rate (referenced to the reversible discharge capacity of $200 \mathrm{mAh} / \mathrm{g}$ at $4.6 \mathrm{~V})$. Charging was done in CCCV mode with $0.05 \mathrm{C}$ cutoff and discharge was performed in $\mathrm{CC}$ mode. Afterwards, the cell was charged to $4.6 \mathrm{~V}(0.5 \mathrm{C}$-rate) and the potential ramped up to $5.0 \mathrm{~V}$ with $2.5 \mathrm{mV} / \mathrm{min}$, followed by a CV step over $3 \mathrm{~h}$.

The reference spectra of Mn-foil, $\mathrm{Mn}$ (II) acetate, $\mathrm{Mn}_{2} \mathrm{O}_{3}, \mathrm{MnO}_{2}$, $\mathrm{Ni}$-foil, $\mathrm{Ni}(\mathrm{II})$ acetate, Co-foil, and $\mathrm{Co}(\mathrm{II})$ acetate were taken from Wandt et al. ${ }^{15}$ Conversion of the measured edge jump to concentrations (in $\mathrm{mol} / \mathrm{L}$ ) was done by measuring a calibration curve. ${ }^{15}$ Therefore, bis(isopropylcyclopentadienyl)manganese, bis(cyclopentadienyl)nickel, and bis(cyclopentadienyl)cobalt (all Sigma-Aldrich) were dissolved in concentrations of $0 \mathrm{mM}$ (background signal of pure LP57 electrolyte), $2 \mathrm{mM}, 4 \mathrm{mM}$, and $20 \mathrm{mM}$ in LP57 electrolyte. The calibration curves were measured in the operando XAS cell in the same geometry, thereby eliminating any differences in X-ray penetration depths. For these calibration measurements, the cells contained only two glass fiber separators and the graphite electrode onto which the beam was focused. Conversion of the measured concentrations to the total moles of transition metals was done by multiplying the former with the volume of the graphite electrode $\left(1 \mathrm{~cm} \times 1 \mathrm{~cm} \times 0.0226 \mathrm{~cm}=0.0226 \mathrm{~cm}^{3}\right)$. Dividing the measured total moles of a given transition metal by the total moles of each transition metal in the NMC electrode then yields the amount of dissolved transition metals in \% from the NMC622 electrode (25.4 mg NMC622 with a molecular weight of $96.9 \mathrm{~g} / \mathrm{mol}$ contain $262 \mu \mathrm{mol}_{\mathrm{NMC}}$, composed of $157 \mu \mathrm{mol}_{\mathrm{Ni}}, 52 \mu \mathrm{mol}_{\mathrm{Mn}}$, and $52 \mu \mathrm{mol}_{\mathrm{Co}}$ ).

The transition metal deposits on a graphite anode were additionally quantified using ICP-OES. Therefore, two NMC622-graphite cells were cycled in XAS cells with the same procedure as described above. Right at the end of the procedure, the graphite electrodes were harvested in the charged state. The copper current collector and glass fiber residues were removed and the graphite was immersed in $0.5 \mathrm{~mL} 65 \%$ $\mathrm{HNO}_{3}$ (analytical grade, Sigma Aldrich) for one week. The Ni, Mn, and Co concentrations in $\mathrm{HNO}_{3}$ were quantified by ICP-OES (Mikroanalytisches Labor Pascher, Remagen, Germany).

Full-cell testing and cyclic voltammetry.-Electrochemical cycling of NMC622-graphite full-cells was performed in Swagelok T-cells assembled in an argon filled glove box $\left(\mathrm{O}_{2}\right.$ and $\mathrm{H}_{2} \mathrm{O}<$ $0.1 \mathrm{ppm}, \mathrm{MBraun}$, Germany), with NMC as working electrode (10 mm diameter) and graphite as counter electrode (11 mm diameter). The areal mass loading of the NMC electrodes was $16.2 \pm 0.6 \mathrm{mg}_{\mathrm{NMC}} / \mathrm{cm}^{2}$ and the one of the graphite electrodes was adapted according to the loading of the NMC electrodes to achieve a constant balancing factor. The areal capacity of the anodes (in $\mathrm{mAh} / \mathrm{cm}^{2}$ ) was 1.2 -fold oversized compared to the cathodes (referenced to the reversible capacities of NMC and graphite measured at a $1 \mathrm{C}$-rate; if referenced to $0.1 \mathrm{C}$, the anode is roughly 1.1-fold oversized). To monitor the potential of both the NMC cathode and the graphite anode, a lithium reference electrode (thickness $0.45 \mathrm{~mm}$, battery grade foil, $99.9 \%$, Rockwood Lithium, USA) was used. Two glass fiber separators (glass microfiber filter, 691, VWR, Germany) punched to a diameter of $11 \mathrm{~mm}$ were 
used between working and counter electrode, and one at the reference electrode (diameter of $10 \mathrm{~mm}$ ). Cells were assembled with $80 \mu \mathrm{L}$ of LP57 electrolyte (1 $\mathrm{M} \mathrm{LiPF}_{6}$ in EC:EMC 3:7 wt/wt, $<20 \mathrm{ppm} \mathrm{H}_{2} \mathrm{O}$, BASF, Germany) placed between working and counter electrode, and $40 \mu \mathrm{L}$ were added to the reference electrode side.

Formation of the cells was done with 2 cycles at $0.1 \mathrm{C}$-rate in the cell voltage range between 3.0 and $4.2 \mathrm{~V}$. The C-rate was referenced to the approximate reversible specific capacity of the NMC of $160 \mathrm{mAh} / \mathrm{g}_{\mathrm{NMC}}$ at $1 \mathrm{C}$ (equating to areal capacitites of $\sim 2.6 \mathrm{mAh} / \mathrm{cm}^{2}$ ). The cells were cycled in a climate chamber (Binder, Germany) at $25^{\circ} \mathrm{C}$ with a battery cycler (Series 4000, Maccor, USA). After the two formation cycles, the cells were opened inside the glovebox and the separators were replaced by two fresh ones in order to remove most of the electrolyte. Then, new electrolyte was added, namely either pure LP57, LP57 + Ni(TFSI $)_{2}$, LP57 + Mn(TFSI $)_{2}$, or LP57 + Co(TFSI $)_{2}$; the resulting concentrations of the transition metals are $30 \mathrm{mM}$ or $60 \mathrm{mM}$. The reasons to use the transition metal TFSI salts are i) because the salts are well soluble in LP57 electrolyte, and ii) because no impact from the TFSI-anion is expected on cell cycling. After reassembly of the cells, they were cycled 298 times at $1 \mathrm{C}$-rate between $3.0 \mathrm{~V}$ and $4.2 \mathrm{~V}$ at $25^{\circ} \mathrm{C}$. At the end of the cycling procedure, the cells were dissembled in a glovebox and an XRD pattern of the NMC622 cathode was measured ex-situ. Any contact to air was prevented by putting the electrode into an airtight sample holder with aluminum windows, as reported previously. ${ }^{28}$ The XRD patterns were obtained in transmission mode using a STOE STADI P diffractometer (STOE, Germany) with Mo- $\mathrm{K}_{\alpha 1}$ radiation $(\lambda=0.70932 \AA)$ and a Mythen $1 \mathrm{~K}$ detector. They were measured at room temperature in a $2 \theta$-range from $6.5-52^{\circ}$ with a step size of $0.015^{\circ}$ and 5 seconds per step.

Cyclic voltammograms (CVs) were recorded in 2032-type coin cells with two glass fiber separators (diameter of $16 \mathrm{~mm}$ ) and $160 \mu \mathrm{L}$ of electrolyte at a scan rate of $0.1 \mathrm{mV} / \mathrm{s}$. CVs were measured in two different set-ups: i) With a conductive carbon electrode coated on a $\mathrm{Cu}$ current collector $\left(1.4-1.7 \mathrm{mg} / \mathrm{cm}^{2}\right)$ versus a lithium counter electrode, using LP57, LP57 + $60 \mathrm{mM} \mathrm{Ni(TFSI})_{2}$, LP57 + $60 \mathrm{mM}$ $\mathrm{Mn}(\mathrm{TFSI})_{2}$, or LP57 $+60 \mathrm{mM} \mathrm{Co}(\mathrm{TFSI})_{2}$. The carbon electrode was polarized starting from $3 \mathrm{~V}$ to $0.01 \mathrm{~V}$ and back to $3 \mathrm{~V}$. ii) With a conductive carbon electrode coated on a stainless steel mesh $\left(1.15 \mathrm{mg}_{\mathrm{C}} / \mathrm{cm}^{2}\right)$ versus an LFP electrode $\left(3.5 \mathrm{mAh} / \mathrm{cm}^{2}\right.$, Custom Cells, Itzehoe, Germany) precharged to 50\% SOC (in LP57), using LP57 + $60 \mathrm{mM} \mathrm{Ni(TFSI})_{2}$ as electrolyte. The carbon electrode was polarized first in a potential range above SEI formation, namely starting from $3 \mathrm{~V}$ to $4 \mathrm{~V}$, down to $1.5 \mathrm{~V}$, and up to $4 \mathrm{~V}$, followed by polarization down to $0.05 \mathrm{~V}$, up to $4 \mathrm{~V}$, and back to $3 \mathrm{~V}$; here, all potential values are calculated vs. $\mathrm{Li}^{+} / \mathrm{Li}$, which was determined by considering a stable LFP potential of $3.45 \mathrm{~V}$ vs. $\mathrm{Li}^{+} / \mathrm{Li}$.

In-situ X-ray diffraction (XRD).- - The in-situ XRD cell used to analyze the changes of the NMC lattice parameters was described in detail elsewhere. ${ }^{14,29}$ The NMC622 working electrode $\left(20.8 \mathrm{mg}_{\mathrm{NMC}} / \mathrm{cm}^{2}\right)$ was coated on aluminum which serves both as a current collector and X-ray window. As counter electrode a lithium metal foil (thickness $0.45 \mathrm{~mm}$, battery grade foil, $99.9 \%$, Rockwood Lithium, USA) was used. Four glass fiber separators (14 mm diameter, glass microfiber filter 691, VWR) and $160 \mu \mathrm{L}$ LP57 electrolyte were placed in between the two electrodes. The in-situ cell was connected to a SP200 potentiostat (SP200, Biologic, France) and charged/discharged at a 0.1 C-rate (referenced to the reversible capacity at $4.3 \mathrm{~V}$ of $180 \mathrm{mAh} / \mathrm{g}$ ). After each one hour period during the charge/discharge process, the cell was put to OCV (open circuit voltage) and XRD patterns were collected at these well-defined states of charge. The in-situ XRD patterns were collected in Bragg-Brentano geometry using nonmonochromatized $\mathrm{Mo}-\mathrm{K}_{\alpha}$ radiation to obtain a higher flux to increase the signal to noise ratios. The diffraction patterns were measured at room temperature in repetition mode, with two repetitions per sample. The patterns were collected in a $2 \theta$-range between $7-52^{\circ}$ with a step size of $0.012^{\circ}$ and 10 seconds dwell time. Data analysis was

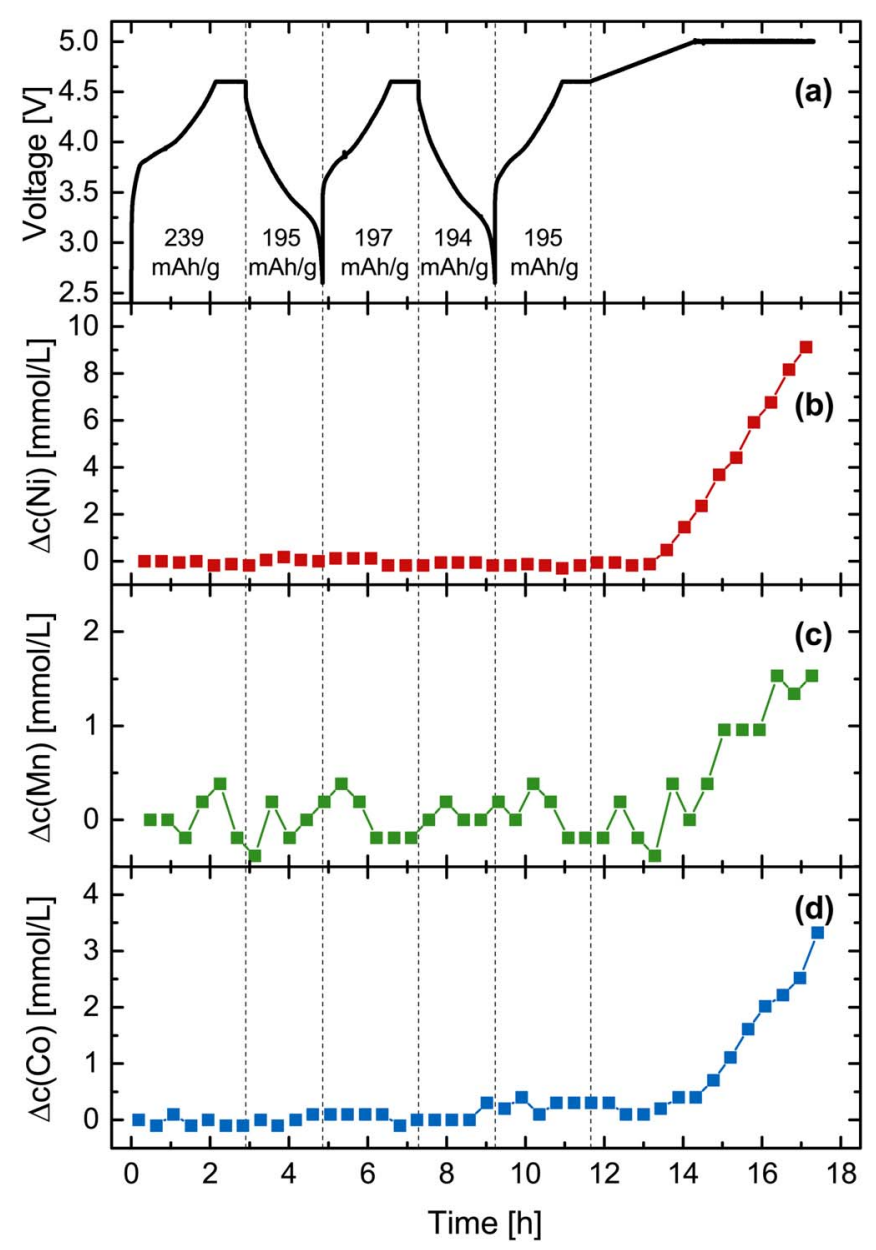

Figure 1. (a) Cell voltage of a NMC622-graphite full cell obtained in the operando XAS cell in LP57 (1 M LiPF 6 in EC:EMC 3:7) electrolyte and measured concentration changes of (b) nickel, (c) manganese, and (d) cobalt on the graphite anode. The first two cycles were conducted using a CCCV charge at $0.5 \mathrm{C}$ to $4.6 \mathrm{~V}$ with a $0.05 \mathrm{C}$ cutoff and a CC discharge to $2.6 \mathrm{~V}$; the third charge was at $0.5 \mathrm{C}$ to $4.6 \mathrm{~V}$, followed by a potential scan at $2.5 \mathrm{mV} / \mathrm{min}$ to $5.0 \mathrm{~V}$, where the potential was held for another $3 \mathrm{~h}$.

performed using WinXPow program package (WinXPow software version 3.0.2.1, 2011, by STOE \& Cie GmbH, Darmstadt, Germany). The determination of the lattice parameters was done using FullProf software (version 3.0, June 2015).

\section{Results}

Operando determination of transition metals deposited on the anode in a NMC622-graphite cell.-Figure 1a depicts the voltage curve of a NMC622-graphite full cell cycled in the operando XAS cell. The first charge and discharge capacities are $239 \mathrm{mAh} / \mathrm{g}_{\mathrm{NMC}}$ and $195 \mathrm{mAh} / \mathrm{g}_{\mathrm{NMC}}$, respectively. In the second cycle, capacities of 197 and $194 \mathrm{mAh} / \mathrm{g}_{\mathrm{NMC}}$ were measured. These capacities match very well the capacity values in our previous publication measured with the same NMC622 material in Swagelok T-cells, showing that the operando XAS cell performs similar to a standard cell set-up. ${ }^{7}$ The concentration changes of $\mathrm{Ni}, \mathrm{Mn}$, and $\mathrm{Co}$ on the graphite anode are shown in Figures $1 \mathrm{~b}-1 \mathrm{~d}$ and were determined by measuring the edge jumps in the X-ray absorption spectra. Conversion of the edge jump to concentrations was done via a calibration with standard solutions (see Experimental section). Because of the constant measurement time for each spectrum at the $\mathrm{Ni}, \mathrm{Mn}$, and Co K-edges, the obtained data for the Mn concentrations have the poorest signal/noise ratio. This is due to the fact that the Mn K-edge $(\sim 6545 \mathrm{eV})$ is at the lowest energy, 

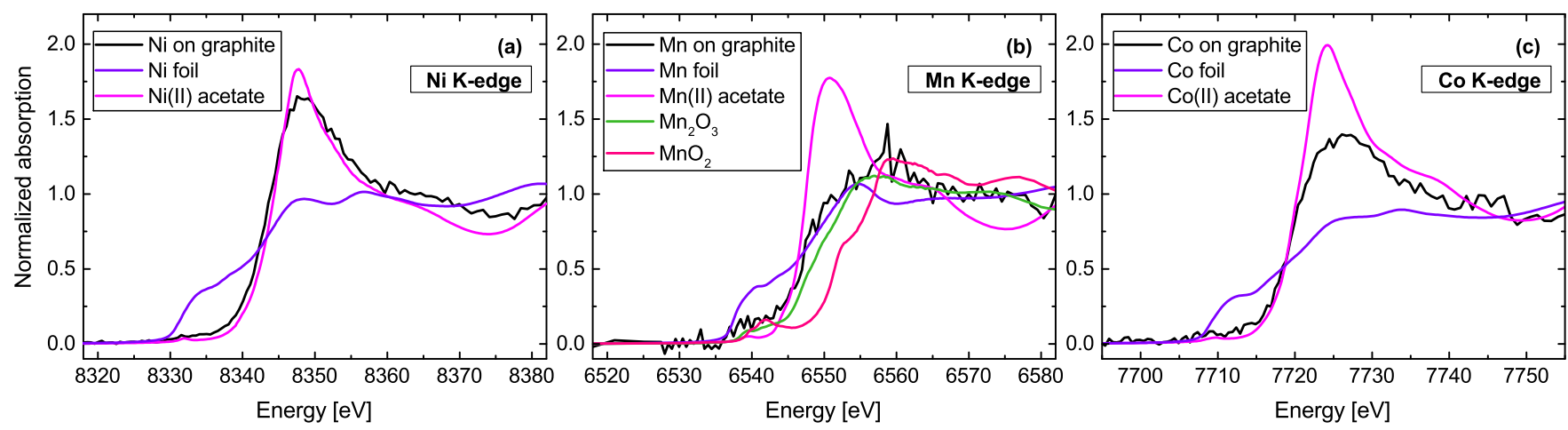

Figure 2. K-edge spectra (black lines) of (a) nickel, (b) manganese and (c) cobalt measured in the operando XAS cell on the lithiated graphite electrode at the end of the experiment shown in Figure 1. The spectra are compared to reference samples containing the transition metals in different oxidation states.

yielding less signal and thus a poorer signal/noise ratio in comparison to the $\mathrm{Ni}(\sim 8340 \mathrm{eV})$ and $\mathrm{Co}(\sim 7715 \mathrm{eV}) \mathrm{K}$-edges.

During cycling to $4.6 \mathrm{~V}$, no significant increases in the transition metal concentrations can be detected. It is important to note that there might be a slow dissolution of transition metals; however, we could not detect it within two cycles using XAS. Wandt et al. observed in a NMC111-graphite cell cycled with the same procedure a slight increase of the Mn concentration of $\sim 20 \mu \mathrm{mol} /(\mathrm{L} \cdot \mathrm{h}),{ }^{15}$ yet this increase is close to the magnitude of the background noise of our experiment. When the cell voltage is ramped up to roughly $4.8 \mathrm{~V}$ (after $\sim 13.5 \mathrm{~h}$ in Figure 1), a steep increase in the concentrations of all three transition metals is observed. By the end of the measurement procedure, the concentrations of $\mathrm{Ni}, \mathrm{Mn}$, and Co have increased by $\sim 9 \mathrm{mM}$, $\sim 1.5 \mathrm{mM}$, and $\sim 3.5 \mathrm{mM}$, respectively. This clearly demonstrates that in case of the Ni-rich NMC622 the dissolved amount of Ni is highest, in agreement with its highest content in the NMC622 material. A conversion of the concentrations to the percentage of dissolved metals from NMC will be presented in the Discussion section.

Figure 2 shows the $\mathrm{Ni}, \mathrm{Mn}$, and Co K-edge spectra. The black curves represent the last spectra measured within the graphite electrode during the electrochemical procedure shown in Figure 1 (spectra measured earlier in the procedure looked the same and are therefore not shown). Reference spectra of the transition metals in their metallic state and in their +II oxidation state are presented in every panel; for $\mathrm{Mn}$, also reference compounds in the oxidation states + III and $+\mathrm{IV}$ are provided. For the spectra measured at the Ni and Co K-edges (Figures $2 \mathrm{a}$ and $2 \mathrm{c}$ ), it can be seen that the edge positions for both metals very well match the edge positions of the +II oxidation state. While for the above discussed reasons the Mn spectrum measured on the graphite electrode is more noisy, the oxidation states 0 and +IV can clearly be excluded. However, due to the very close edge positions and the rather noisy spectrum, we cannot distinguish between a Mn oxidation state of + II or + III, or even a mix of both. The observed oxidation states of the different metals will be discussed in greater detail and compared to the reports in the literature in the Discussion section.

Reduction potentials of $\mathrm{Ni}^{2+}, \mathrm{Mn}^{2+}$, and $\mathrm{Co}^{2+}$. - The reduction potentials of $\mathrm{Ni}, \mathrm{Mn}$, and Co in LP57 electrolyte were determined by cyclic voltammetry on a conductive carbon (Super C65) electrode vs. a lithium metal counter electrode in a standard coin cell. Figure 3 illustrates the measured specific current as a function of the voltage of the conductive carbon working electrode. For pure LP57 electrolyte (black line), without the addition of any transition metal, one reduction peak at $\sim 0.7 \mathrm{~V}$ vs. $\mathrm{Li}^{+} / \mathrm{Li}$ can be observed, stemming from the reduction of electrolyte forming the SEI on the carbon surface..$^{30,31}$ Below $\sim 0.4 \mathrm{~V}$, the reductive specific current increases, which stems from lithium intercalation into the graphitic regions of the conductive carbon; its deintercalation can be observed as the positive peak at $\sim 0.08 \mathrm{mV}$. As expected, no reversible oxidation peak corresponding to the reductive SEI formation current exists, due to the irreversibility of the SEI forming reaction. When $\mathrm{Ni}, \mathrm{Mn}$, or Co $(60 \mathrm{mM}$ solutions of $\mathrm{Ni}(\mathrm{TFSI})_{2}, \mathrm{Mn}(\mathrm{TFSI})_{2}$, or $\mathrm{Co}(\mathrm{TFSI})_{2}$ ) is added to LP57, the same reduction peak for SEI formation is observed as for pure LP57 without any significant changes, yet an additional reductive peak can be observed at higher potentials which correspond to the reduction of the transition metals. The maxima of the reduction peaks vs. $\mathrm{Li}^{+} / \mathrm{Li}$ are at $2.22 \mathrm{~V}(\mathrm{Ni}$, red line), $1.27 \mathrm{~V}(\mathrm{Mn}$, green line), and $2.52 \mathrm{~V}(\mathrm{Co}$, blue line). Compared to the standard reduction potentials in aqueous media (if referenced to $\mathrm{Li}^{+} / \mathrm{Li}$, at $2.80 \mathrm{~V}\left(\mathrm{Ni} / \mathrm{Ni}^{2+}\right), 1.87 \mathrm{~V}\left(\mathrm{Mn} / \mathrm{Mn}^{2+}\right.$ ) and $\left.2.77 \mathrm{~V}\left(\mathrm{Co} / \mathrm{Co}^{2+}\right)^{32}\right)$, the measured values are slightly lower, presumably due to differences in the solvation energies of $\mathrm{H}_{2} \mathrm{O}$ and $\mathrm{EC} ;{ }^{15,33}$ nevertheless, the $\sim 1 \mathrm{~V}$ lower reduction potential of Mn compared to $\mathrm{Ni}$ and Co applies to both solvent environments. We believe that due to the good solubility of the TFSI-salts in the electrolyte and the rather low concentration of the TFSI-anion compared to the $\mathrm{PF}_{6}^{-}$-anions the reduction peaks corresponding to the transition metal reduction are not significantly influenced by the presence of the TFSI-anion. This is supported by the previous observation in the literature that the anion does also not affect the gas evolution in the course of SEI formation on graphite when the electrolyte contains $\mathrm{LiPF}_{6}$ or LiTFSI as conductive salt. ${ }^{31,34,35}$ Note that during the oxidative scan in Figure 3, we do not observe any peak corresponding to the re-oxidation of the deposited metals on the carbon surface. This is somewhat surprising since one could expect that the reduction and oxidation of the transition metals

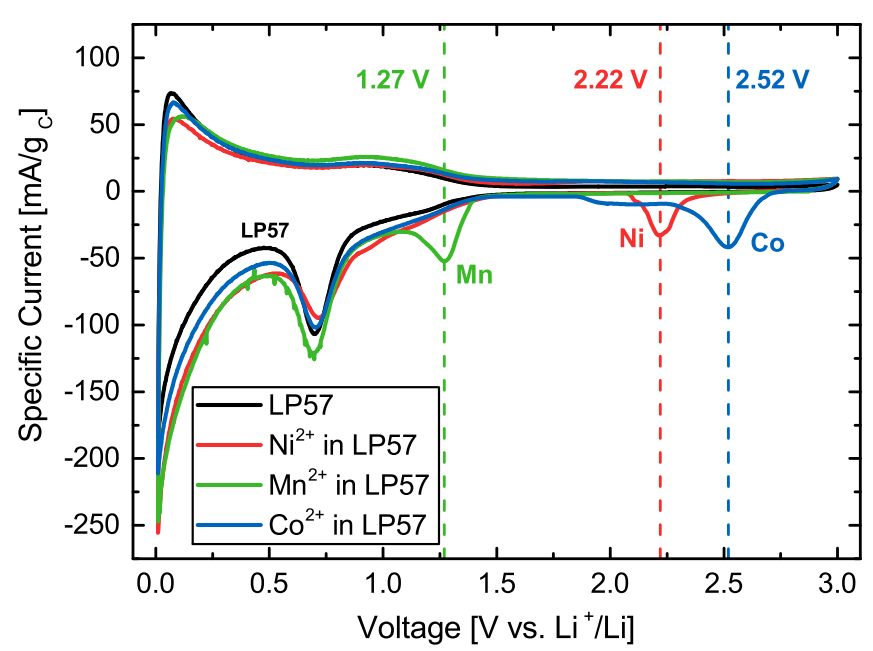

Figure 3. First cycle of a cyclic voltammogram of a Super C65 electrode $\left(1.4-1.7 \mathrm{mg} / \mathrm{cm}^{2}\right)$ in LP57 (black), LP57 + $\left.60 \mathrm{mM} \mathrm{Ni(TFSI}\right)_{2}$ (red), LP57 + $60 \mathrm{mM} \mathrm{Mn(TFSI})_{2}$ (green), and LP57 + $\left.60 \mathrm{mM} \mathrm{Co(TFSI}\right)_{2}$ (blue). The potential scan at $0.1 \mathrm{mV} / \mathrm{s}$ was started close to $\mathrm{OCV}$ at $3 \mathrm{~V} \mathrm{vs}$. $\mathrm{Li}^{+} / \mathrm{Li}$, from where the carbon electrode was first polarized negatively to $0.01 \mathrm{~V}$ vs. $\mathrm{Li}^{+} / \mathrm{Li}$ and then back to $3 \mathrm{~V}$ vs. $\mathrm{Li}^{+} / \mathrm{Li}$. 


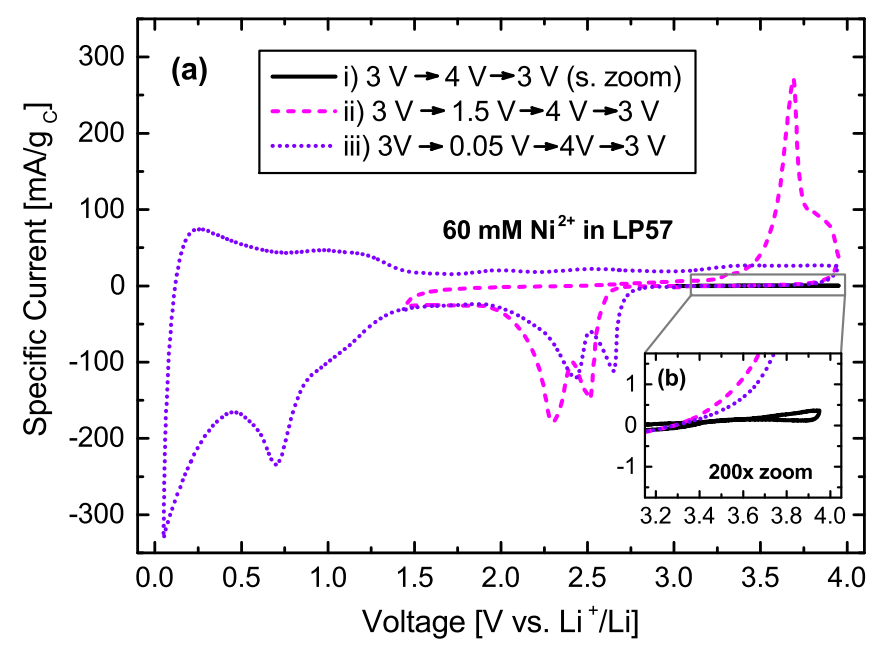

Figure 4. Cyclic voltammograms of a Super C65 electrode $\left(1.15 \mathrm{mg} \mathrm{C} / \mathrm{cm}^{2}\right)$ cycled vs. LFP $(50 \% \text { SOC) in LP57 }+60 \mathrm{mM} \mathrm{Ni(TFSI})_{2}$. The experiment was started close to $\mathrm{OCV}$ at $3 \mathrm{~V}$ vs. $\mathrm{Li}^{+} / \mathrm{Li}$. The carbon electrode was polarized at a scan rate of $0.1 \mathrm{mV} / \mathrm{s}$ in three steps: i) from $3 \mathrm{~V}$ to $4 \mathrm{~V} \mathrm{vs}$. $\mathrm{Li}^{+} / \mathrm{Li}$ and back to $3 \mathrm{~V}$ (black solid line); then, ii) from $3 \mathrm{~V}$ to $1.5 \mathrm{~V}$, up to $4 \mathrm{~V}$ and back to $3 \mathrm{~V}$ (pink dashed line); finally, as a last step, iii) from $3 \mathrm{~V}$ to $0.05 \mathrm{~V}$, up to $4 \mathrm{~V}$, and back to $3 \mathrm{~V}$ (purple dotted line).

should be a reversible process. We also repeated the experiments with an electrolyte containing only $30 \mathrm{mM}$ of the transition metals and observed qualitatively the same results, yet of course with smaller reduction peaks of the transition metals (data not shown).

To better understand this observation and the effect of the SEI on the reversibility of the metal reduction and oxidation, we modified the experimental set-up: i) Aiming to understand if the absence of a transition metal oxidation peak in Figure 3 may be caused by a high overpotential for the transition metal oxidation, the conductive carbon was coated on a stainless steel current collector mesh in order to allow scanning to potentials $>3 \mathrm{~V}$ (not possible with a copper current collector due to its limited oxidative stability). ii) The Li counter electrode was replaced by an LFP counter electrode, which was precharged to $50 \%$ SOC and therefore has a stable potential at $\sim 3.45 \mathrm{~V}$ vs. $\mathrm{Li}^{+} / \mathrm{Li}$, at which no transition metal reduction and also no electrolyte oxidation/reduction is possible. The results of the $\mathrm{CV}$ experiment with this modified set-up are shown in Figure 4. The voltage of the carbon electrode vs. $\mathrm{Li}^{+} / \mathrm{Li}$ in Figure 4 is calculated by considering that the potential of the partially delithiated LFP electrode is stable at $3.45 \mathrm{~V}$ vs. $\mathrm{Li}^{+} / \mathrm{Li}$. First, we scanned the potential of the conductive carbon electrode from its OCV value at $\sim 3 \mathrm{~V}$ in LP57 + $60 \mathrm{mM} \mathrm{Ni}(\mathrm{TFSI})_{2}$ to $4 \mathrm{~V}$ vs. $\mathrm{Li}^{+} / \mathrm{Li}$ (black solid line in Figure 4) in order to test if an oxidation of the dissolved $\mathrm{Ni}^{2+}$ to $\mathrm{Ni}^{3+}$ or even $\mathrm{Ni}^{4+}$ might be possible. As can be seen in the inset of Figure 4 (black line), no current is observed up to $4 \mathrm{~V} \mathrm{vs} . \mathrm{Li}^{+} / \mathrm{Li}$, excluding the oxidation of $\mathrm{Ni}^{2+}$. Subsequently, the carbon electrode was polarized to a potential of $1.5 \mathrm{~V} \mathrm{vs.} \mathrm{Li}^{+} / \mathrm{Li}$ (pink dashed line), so that $\mathrm{Ni}$ can again be observed to be reduced on the carbon surface at a similar potential as in Figure 3, while at the same time the formation of the SEI can be avoided. Unexpectedly, the reduction of $\mathrm{Ni}^{2+}$ is split into two peaks, which was also observed in a repeat measurement (not shown). Even though we currently have no explanation for this observation, we believe that the peaks are due to Ni reduction because of the very similar reduction potentials in Figure 3 and Figure 4. Afterwards, the carbon electrode potential is scanned back to $4 \mathrm{~V}$ vs. $\mathrm{Li}^{+} / \mathrm{Li}$. whereby the re-oxidation of deposited $\mathrm{Ni}$ is observed at $3.7 \mathrm{~V} \mathrm{vs}$. $\mathrm{Li}^{+} / \mathrm{Li}$ (pink dashed line). The total coulombs under the reduction and oxidation peak correspond to 1.03 As and 0.99 As, respectively. The almost identical amounts of charge under reduction and oxidation peak prove the full reversibility of the Ni reduction and oxidation. Based on the total coulombs and a $2 \mathrm{e}^{-}$reduction $\left(\mathrm{Ni}^{2+}\right.$ to $\left.\mathrm{Ni}(0)\right)$ roughly $60 \%$ of the $\mathrm{Ni}^{2+}$ ions in

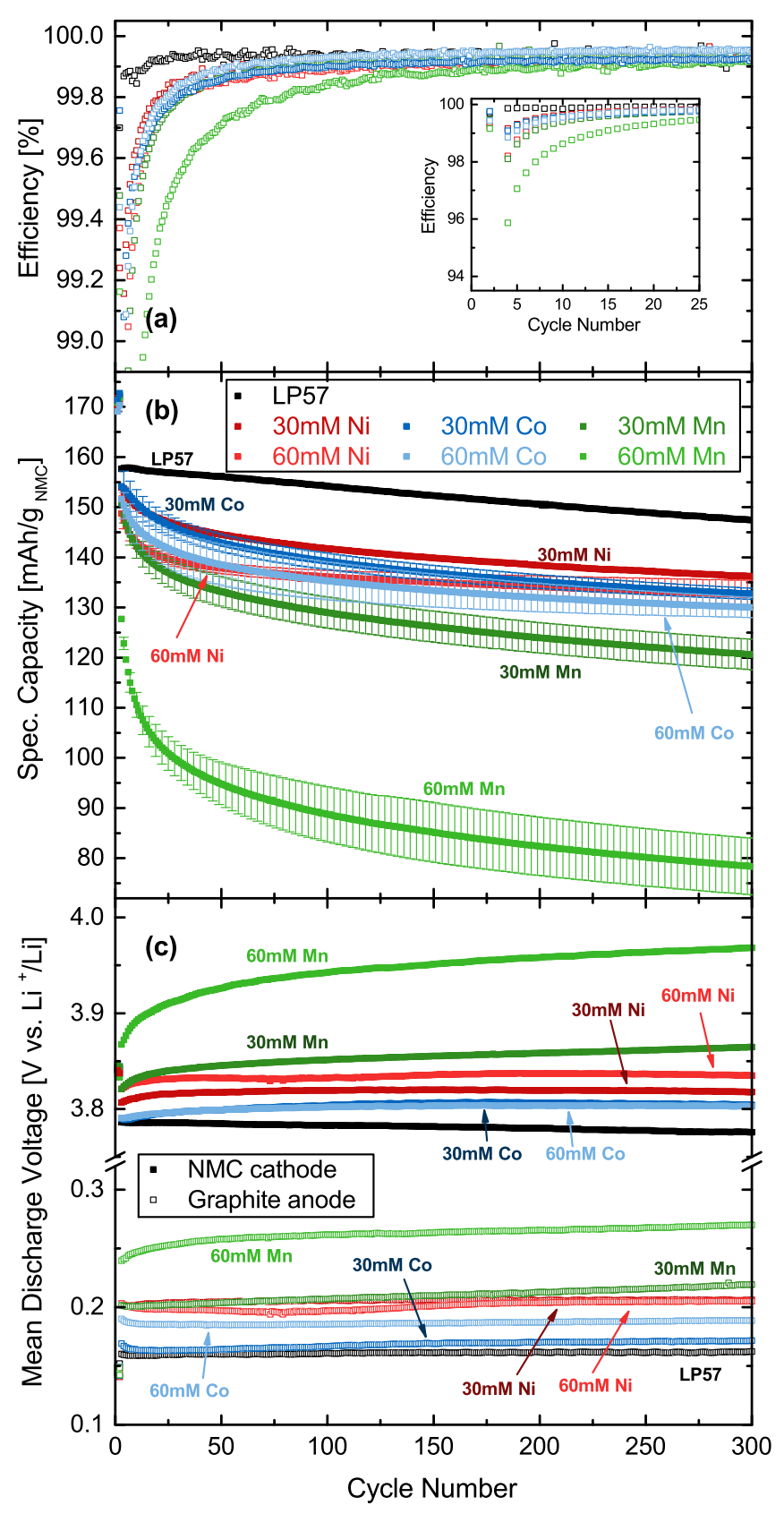

Figure 5. (a) Coulombic efficiency, (b) specific discharge capacity, and (c) mean discharge voltage of NMC cathode and graphite anode vs. cycle number of NMC622-graphite cells containing LP57 (1 M LiPF 6 in EC:EMC 3:7) (black), LP57 + Ni(TFSI) 2 (red), LP57 + Mn(TFSI) $)_{2}$ (green), or LP57 + $\mathrm{Co}(\mathrm{TFSI})_{2}$ (blue). The concentrations of $\mathrm{Ni}^{2+}, \mathrm{Mn}^{2+}$, and $\mathrm{Co}^{2+}$ were $30 \mathrm{mM}$ or $60 \mathrm{mM}$. The cells were cycled between $3.0 \mathrm{~V}$ and $4.2 \mathrm{~V}$. Formation was done at $0.1 \mathrm{C}$-rate in pure LP57; subsequently, the electrolyte was replaced and the cells were cycled at $1 \mathrm{C}$-rate and $25^{\circ} \mathrm{C}$. For each condition, two independent cells were run and the data in (a) and (b) represent the average of two cells (the error bars in (b) represent the standard deviation between the two cells, which are left out for clarity in (a)). Panel (c) shows the mean discharge voltages of one representative cell for each condition.

the electrolyte were reduced. Probably not all of the $\mathrm{Ni}^{2+}$ ions in the electrolyte were reduced, because a rather large electrolyte excess was used and some of the electrolyte could flow into the hollow space of the cell making it inaccessible for the electrochemical reaction. In the last cycle, the electrode was polarized down to $50 \mathrm{mV}$ vs. $\mathrm{Li}^{+} / \mathrm{Li}$ (purple dotted line), in which case both Ni reduction and SEI formation are observed. However, during the subsequent positive scan 


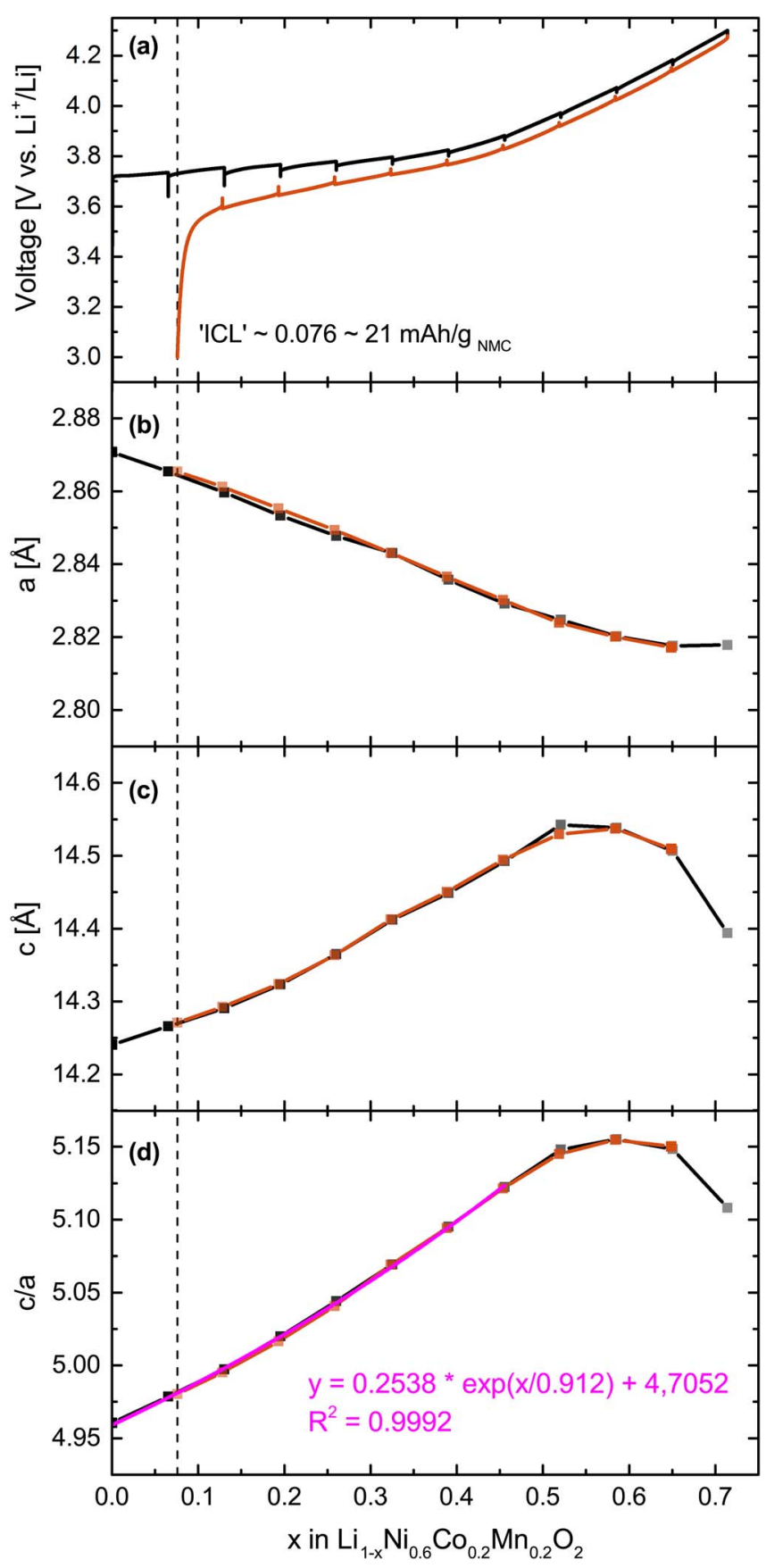

Figure 6. (a) Cell voltage of a NMC622-Li cell obtained at $0.1 \mathrm{C}$ with intermittent OCV periods in an in-situ XRD cell in LP57 electrolyte, (b) lattice parameter $a$, (c) lattice parameter $c$, and (d) $c / a$ ratio as a function of the degree of delithiation $\mathrm{x}$ as defined by $\mathrm{Li}_{1-\mathrm{x}} \mathrm{Ni}_{0.6} \mathrm{Co}_{0.2} \mathrm{Mn}_{0.2} \mathrm{O}_{2}$. The voltage profile and lattice parameters during charge and discharge are marked in black and orange, respectively. The exponential fit between $\mathrm{x}=0$ and $\mathrm{x}=0.46$ (pink line) yields the fitting equation $\mathrm{c} / \mathrm{a}=0.2538 \cdot \exp (\mathrm{x} / 0.912)+4.7052$, with $\mathrm{R}^{2}=0.9992$

back to $4 \mathrm{~V}$ vs. $\mathrm{Li}^{+} / \mathrm{Li}$, we do not anymore observe an oxidation peak corresponding to $\mathrm{Ni}$ oxidation (purple dotted line), suggesting that a reversible oxidation of reduced $\mathrm{Ni}$ in the presence of an SEI does not occur. This clearly demonstrates that the SEI has a severe impact on the reversibility of the transition metal reduction/oxidation. We will discuss this in more detail in the Discussion section.

Electrochemical cycling of NMC622-graphite cells.-To investigate and compare the impact of $\mathrm{Ni}, \mathrm{Mn}$, and $\mathrm{Co}$ on the electrochem- ical performance of NMC622-graphite cells, electrolytes containing a concentration of $30 \mathrm{mM}$ and $60 \mathrm{mM}$ of Ni(TFSI $)_{2}, \mathrm{Mn}(\mathrm{TFSI})_{2}$, or $\mathrm{Co}(\mathrm{TFSI})_{2}$ were used for cell cycling. The formation of the cells (initial two cycles) was always done in pure LP57 electrolyte, then the electrolyte was replaced in the discharged state with the transition metal containing LP57, upon which the cells were reassembled for further cycling (see Experimental section). This is intended to mimic the realistic scenario in which the SEI is already present on the graphite anode before significant amounts of transition metals dissolve from the NMC cathode during extended charge/discharge cycling. Note that the cells cycled in pure LP57 were also reassembled after the two formation cycles in order to verify that the SEI is not being damaged when the electrolyte used during formation (LP57) is replaced by the one used during extended cycling (again LP57 or LP57 with the addition of the transition metal salts). The fact that we did not observe any impact of cell disassembly and reassembly after formation on the electrochemical behavior of the cells proves that the SEI stayed intact during this procedure. Additionally, in a previous study we used the same cycling test with the same NMC622 material and LP57, yet, without a cell opening after formation and observed exactly the same capacity loss after 300 cycles within an error of $\pm 1 \mathrm{mAh} / \mathrm{g}{ }^{7}$

Figure 5 shows the results of NMC622-graphite cells cycled between $3.0 \mathrm{~V}$ and $4.2 \mathrm{~V}$ in pure LP57 (black), and in LP57 containing $\mathrm{Ni}(\mathrm{TFSI})_{2}$ (red), Mn(TFSI) $)_{2}$ (green), or $\mathrm{Co}(\mathrm{TFSI})_{2}$ (blue). For all cells, a specific discharge capacity of $171 \pm 1 \mathrm{mAh} / \mathrm{g}$ was obtained in the second formation cycle at a $0.1 \mathrm{C}$-rate. In the third cycle which is the first cycle conducted at $1 \mathrm{C}$, the cells containing pure LP57 (black) reached a discharge capacity of $157.6 \mathrm{mAh} / \mathrm{g}$ and faded by $\sim 6.0 \%$ to $148.2 \mathrm{mAh} / \mathrm{g}$ within 298 cycles at a $1 \mathrm{C}$-rate. The measured specific capacities of the third and $300^{\text {th }}$ cycles (i.e., the first and the $298^{\text {th }}$ cycle at 1 C) of the cells cycled in transition metal containing electrolyte are summarized in Table I. It can be observed that in the third cycle the specific capacities are significantly lower for cells with transition metal ions than the ones obtained for the cells in pure LP57. This indicates that significant irreversible reactions occur right after the transition metals are added into the cell. Upon cycling, the capacity fading in the presence of added transition metals is much more significant within the first 50 cycles than from cycle 50 to 300 , indicating that the detrimental effect of the transition metals on the capacity fading rate is reduced during cycling (Figure 5). Furthermore, the specific capacity decay is fairly similar for all cells at cycle numbers $>100$. Overall, the capacity loss over 298 cycles at $1 \mathrm{C}$ if referenced to the initial capacity at $1 \mathrm{C}\left(3^{\text {rd }}\right.$ cycle $)$ in pure LP57 ranges between $14-18 \%$ in the presence of 30 and $60 \mathrm{mM} \mathrm{Ni}^{2+}$ and $\mathrm{Co}^{2+}$ ions (see last column in Table I). The effect of $\mathrm{Mn}^{2+}$ is clearly more detrimental, as already suggested in the literature: ${ }^{36}$ the capacity fading induced by $30 \mathrm{mM}$ $\mathrm{Mn}^{2+}$ ions is $\sim 1.5$-fold higher than that of $\mathrm{Ni}^{2+}$ and $\mathrm{Co}^{2+}$, and even $\sim 3$-fold higher in the presence $60 \mathrm{mM} \mathrm{Mn}^{2+}$ ions (see last column in Table I). These observations are in good agreement with the measured coulombic efficiencies (Figure 5a). In particular, low efficiencies were observed at cycle numbers $<50$ only for the cells containing transition metals, particularly for $\mathrm{Mn}$, and similar coulombic efficiencies to the pure LP57 cells at cycle numbers $>100$.

Figure $5 \mathrm{c}$ depicts the charge averaged mean discharge voltages of the NMC (full squares) and the graphite (open squares) electrodes vs. the Li reference electrode. The charge averaged mean discharge voltage is defined as:

$$
\overline{\mathrm{V}}_{\text {discharge }}=\int \mathrm{V}_{\text {discharge }} \cdot \mathrm{dq}_{\text {discharge }} / \int \mathrm{dq}_{\text {discharge }}
$$

The major influences on $\overline{\mathrm{V}}_{\text {discharge }}$ during electrochemical cycling are i) changes in the electrode impedance, and ii) changes due to the relative shift in the state-of-charge (SOC) window of the positive and negative electrode (e.g., caused by the loss of active lithium). In the literature, it was shown that transition metals deposited on the graphite anode cause the loss of active lithium by irreversible side reactions on the anode, leading to additional SEI formation. ${ }^{17,19-24}$ The latter was hypothesized to lead to an impedance growth on the anode. ${ }^{17,20}$ On the NMC cathode, a loss of cycleable Li would lead to an increase in $\bar{V}_{\text {discharge }}^{\text {cathode }}$ due to an upshift of the SOC window, whereas 
Table I. Measured specific discharge capacities of the 3rd and $300^{\text {th }}$ cycle (both at $1 \mathrm{C}$-rate) of the cells depicted in Figure 5 (average values for two repeat measurements). The last column shows the capacity loss referenced to the initial capacity at $1 \mathrm{C} \mathrm{(3}{ }^{\text {rd }}$ cycle) in pure LP57 electrolyte.

\begin{tabular}{cccc} 
Cell characteristics & Cycle $3[\mathrm{mAh} / \mathrm{g}]$ & Cycle 300 $[\mathrm{mAh} / \mathrm{g}]$ & C-loss wrt. pure LP57 $3^{\text {rd }} \rightarrow 300^{\text {th }}$ cycle $[\%]$ \\
\hline LP57 & 158 & 148 & $\sim 6$ \\
$30 \mathrm{mM} \mathrm{Ni}$ & 153 & 136 & $\sim 14$ \\
$30 \mathrm{mM} \mathrm{Mn}$ & 150 & 120 & $\sim 24$ \\
$30 \mathrm{mM} \mathrm{Co}$ & 154 & 133 & $\sim 16$ \\
$60 \mathrm{mM} \mathrm{Ni}$ & 149 & 134 & $\sim 15$ \\
$60 \mathrm{mM} \mathrm{Mn}$ & 128 & 19 & $\sim 50$ \\
$60 \mathrm{mM} \mathrm{Co}$ & 152 & 130 & $\sim 18$
\end{tabular}

impedance growth would lead to a decrease in $\overline{\mathrm{V}}_{\text {discharge }}^{\text {cathode }}$ In contrast, on the graphite anode, both a loss of cycleable $\mathrm{Li}$ as well as impedance growth would result in increasing values of $\overline{\mathrm{V}}_{\text {discharge }}^{\text {anode }}$. For the cells with pure LP57, $\overline{\mathrm{V}}_{\text {discharge }}^{\text {cathode }}$ and $\overline{\mathrm{V}}_{\text {discharge }}^{\text {anode }}$ are nearly constant, indicating only minor changes in electrode impedance and also rather small amounts of cycleable lithium loss (black symbols in Figure 5c). However, $\overline{\mathrm{V}}_{\text {discharge }}^{\text {cathode }}$ of the NMC electrodes in the transition metal containing cells is clearly higher, indicating that the origin of the specific capacity fading must at least to a significant part be related to the loss of cycleable lithium. The increase in $\overline{\mathrm{V}}_{\text {discharge }}^{\text {catho }}$ is most significant within the first cycles after transition metal addition, particularly for the cells containing $\mathrm{Mn}^{2+}$ ions, consistent with what would be expected based on the data in Figures 5a and 5b. Qualitatively, the evolution of the $\bar{V}_{\text {discharge }}^{\text {anode }}$ increase is very similar to that of $\bar{V}_{\text {discharge }}^{\text {cathode }}$ in transition metal containing cells. However, as $\overline{\mathrm{V}}_{\text {discharge }}^{\text {anode }}$ would increase for both a loss of cycleable Li and an increase in anode impedance, these two possible effects cannot be deconvoluted on the basis of $\overline{\mathrm{V}}_{\text {discharge }}^{\text {anode }}$. We will discuss this in greater detail in the Discussion section.

In order to quantify the loss of active lithium and thereby evaluate if this aging mechanism is responsible for all the capacity fading observed in Figure 5, we determined the Li-loss by measuring the lithium content in the NMC electrodes after the 300 cycles (in the discharged state) using a similar ex-situ XRD based analysis as was reported earlier by our group. ${ }^{14}$ In brief, as the NMC electrode is capacity limiting in the cells depicted in Figure 5, the lithium content of the NMC electrode at the end of discharge after one or several charge/discharge cycles would have to remain constant in the absence of a cycleable lithium loss. However, due to side reactions, e.g., SEI formation on the anode, cycleable lithium can be lost irreversibly, ${ }^{37-41}$ in which case the lithium content of the NMC electrode at the end of discharge would decrease. As the lattice parameters of NMC vary with lithium content, the amount of irreversibly lost lithium can be determined by measuring the lattice parameters of the NMC at the end of discharge after the cycle life test, if a quantitative correlation between NMC lattice parameters and lithium content can be established. In this case, the change in NMC lithium content of a discharged NMC electrode before and after the cycle life test can be compared to the observed capacity loss in order to determine whether or not the loss of active lithium is the dominating aging mechanism.

To obtain the correlation of the degree of delithiation (defined as $\mathrm{x}$ in $\mathrm{Li}_{1-\mathrm{x}} \mathrm{Ni}_{0.6} \mathrm{Mn}_{0.2} \mathrm{Co}_{0.2} \mathrm{O}_{2}$ ) and the lattice parameters, XRD patterns of an NMC622 electrode charged vs. metallic lithium were measured

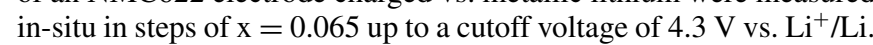
Subsequently, the cell was discharged in equal steps to a cutoff of $3 \mathrm{~V}$ vs. $\mathrm{Li}^{+} / \mathrm{Li}$. The voltage profile of the NMC622-Li cell is shown in Figure 6a, with the spikes indicating the SOCs at which the cell was put into OCV to measure the XRD pattern (due to the absence of a current during OCV, the cell potential relaxes, yielding the clearly visible spikes in the cell voltage profile). Figure 6a shows that the NMC cannot be fully relithiated at the end of discharge even after the first charge/discharge cycle, with $\mathrm{x} \sim 0.076$ missing for a complete relithiation ( $\equiv 21 \mathrm{mAh} / \mathrm{g}_{\mathrm{NMC}}$, corresponding to a composition of $\mathrm{Li}_{0.924} \mathrm{Ni}_{0.6} \mathrm{Mn}_{0.2} \mathrm{Co}_{0.2} \mathrm{O}_{2}$ ); this is due to a kinetic hindrance to fully relithiate the NMC structure and constitutes the so-called irreversible capacity loss (ICL) of NMC cathodes. ${ }^{14,42,43}$
Figures $6 \mathrm{~b}-6 \mathrm{~d}$ show the corresponding evolution of the lattice parameters $a$ and $c$, as well as their ratio (the corresponding X-ray diffractograms will be shown in Figure 7). Lattice parameter $a$ decreases in a fairly linear fashion until $\mathrm{x}=0.5$ and then stays rather constant between $\mathrm{x}=0.6$ and $\mathrm{x}=0.7$. In contrast, the $c$ lattice parameter increases exponentially until $\mathrm{x}=0.5$ and then decreases again for $x>0.6$. Qualitatively, the variation of the lattice parameters of NMC622 vs. $x$ (Figure 6) is very similar to the ones reported for NMC $111^{14,44}$ and NMC811. ${ }^{45}$ In general, a change of the $a$-parameter indicates changes in the metal-metal or oxygen-oxygen distances and changes of the $c$-parameter represent a changing interlayer distance. ${ }^{44}$ Therefore, the decreasing $a$-parameter for $\mathrm{x}<0.5$ can be explained by the increasing oxidation state of the transition metals upon lithium extraction, causing stronger metal-oxygen interaction. Concurrently, the increase of the $c$-parameter can be explained by stronger repulsion of the oxygen layers when lithium is removed from the NMC structure, while the subsequently decreasing $c$-parameter at $\mathrm{x}>0.6$ has been linked to an increasing covalency between the metal and the oxygen, ${ }^{44,46}$ i.e., to a reduced negative charge density of the oxygen. This is in agreement with the reports by Yoon et al. and Petersburg et al., who reported an oxidation of the lattice oxygen in NMC111 at SOCs $>45 \% .{ }^{47,48}$ Additionally, lattice oxygen oxidation was also reported for the oxides $\mathrm{Li}_{2} \mathrm{Ru}_{1-\mathrm{y}} \mathrm{Sn}_{\mathrm{y}} \mathrm{O}_{3}{ }^{49}$ and $\mathrm{Li}_{2} \mathrm{IrO}_{3} .{ }^{50}$ Ultimately, the oxidation of the oxygen is the likely reason for the release of lattice oxygen for NMC622 at $x \geq 80 \% .^{7,51,52}$ As shown by the pink line in Figure $6 \mathrm{~d}$, the $c / a$ ratio in the region of $\mathrm{x}<0.5$ can be fitted by an exponential function, which will serve as calibration curve to determine the lithium content of the discharged NMC electrodes after the cycle life test shown in Figure 5 by means of ex-situ XRD measurements. The correlation between the loss of cycleable lithium and the capacity loss will be presented in Table III in the Discussion section.

The measured X-ray diffractograms of the cell shown in Figure 6 are depicted in Figure 7. Besides the NMC phase, the only additional reflections originate from the aluminum window of the in-situ XRD cell and are marked with a star (Figure 7a). The crystal structure of the NMC622 can be indexed with the space group R $\overline{3} \mathrm{~m}$. The black and orange diffractograms are measured during charge and discharge (Figure 6a), respectively, and are stacked vertically for better visibility in the order they were measured, i.e., with decreasing lithium content during the first charge (black lines) and increasing lithium content during the subsequent discharge (organge lines). Figures $7 \mathrm{~b}$ and $7 \mathrm{c}$ show zooms into the regions of 7.9-9.6 $2 \theta$ and 27.7-31.2 $2 \theta$. During delithiation, the (003) reflection of the NMC622 (Figure $7 b$ ) is gradually shifting towards lower angles until $50-60 \%$ of the lithium is removed from the layered NMC structure, representing an increasing unit cell along the c-axis as seen in Figure $6 c$ (the (003) reflection has no contribution from the unit cell $a$-parameter and depends only on the $c$-parameter). Very prominent is the large shift of the (003) reflection to higher angles between $65-72 \%$ lithium extraction (second last and last diffractogram measured during charge (black)), representing the contraction of the unit cell along the c-axis at rather high states-of-charge (Figure 6c), similar to the behavior reported for NMC $111^{14,44}$ and NMC811. ${ }^{45}$ Upon discharge, the measured angle of the (003) reflection initially decreases very rapidly, followed by a gradual and continuous increase until the end of discharge. A very 

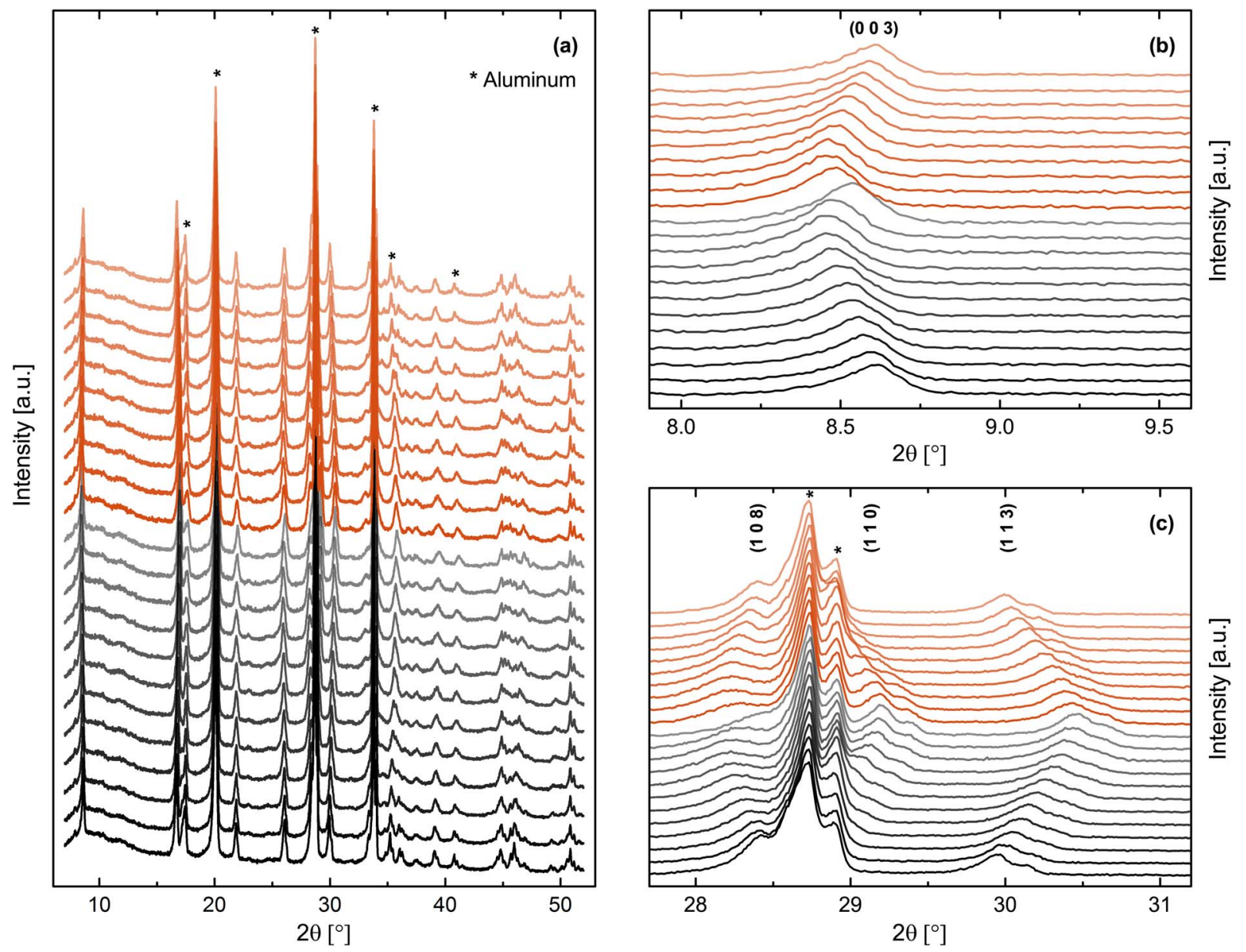

Figure 7. X-ray diffractograms of the NMC622 measured in-situ in the NMC622-Li cell (Figure 6) for different $2 \theta$ ranges: (a) over the entire range of 7-52 $2 \theta$; (b) zoom into the 7.9-9.6 $2 \theta$ range showing the (003) reflection; (c) zoom into the $27.7-31.2^{\circ} 2 \theta$ range showing the (108), (110), and (113) reflection. The diffractograms are stacked vertically for better visibility. From bottom to top, the black diffractograms are stacked with growing SOC during the first charge, followed by the orange diffractograms measured during the subsequent discharge stacked in order of decreasing SOC. All visible reflections stemming from the aluminum window of the in-situ XRD cell are labeled with a star. The reflections are indexed with the R $\overline{3} \mathrm{~m}$ space group of the NMC crystal structure.

similar shift during charge/discharge is observed for the (108) reflection shown in Figure 7c. In contrast to the (003) and (108) reflections, the (110) and (113) reflections shift continuously to higher angles during charge and to lower angles during discharge. Note, that the (110) reflection is independent of the $c$-parameter, whereas the (113) reflection is only slightly influenced by the $c$-parameter. Therefore, a shift to higher angles during charge corresponds to a decreasing $a$-parameter as depicted in Figure $6 \mathrm{~b}$ (and vice versa during discharge).

Comparing the positions of the reflections in the first diffractogram (bottom, fully lithiated NMC) with the last one at the end of discharge (top), the maxima of the reflections move almost completely back to their initial positions, reflecting the high reversibility of the lithium de/intercalation. The remaining offsets, however, are due to the kinetic hindrance to fully relithiate the NMC structure, so that after discharge the NMC composition can be written as $\mathrm{Li}_{0.924} \mathrm{Ni}_{0.6} \mathrm{Mn}_{0.2} \mathrm{Co}_{0.2} \mathrm{O}_{2}$ (see Figure $6 a) .{ }^{14}$

\section{Discussion}

Quantification of deposited transition metals on a graphite anode.-The concentrations of deposited $\mathrm{Ni}, \mathrm{Mn}$, and $\mathrm{Co}$ on the graphite anode (Figure 1) can be correlated with the total amount of the metals in NMC. With the graphite electrode thickness of $226 \mu \mathrm{m}$ and an area of $1 \times 1 \mathrm{~cm}^{2}$, the volume of the graphite electrode is $22.6 \mu \mathrm{L}$. Multiplying the measured concentration changes with the volume of the graphite electrode yields the moles of deposited metals inferred from the operando XAS analysis to be $0.2 \mu$ mol $_{\mathrm{Ni}(\mathrm{XAS})}$, $0.04 \mu \mathrm{mol}_{\mathrm{Mn}(\mathrm{XAS})}$, and $0.08 \mu \mathrm{mol}_{\mathrm{Co}(\mathrm{XAS})}$, which includes the amount of transition metals dissolved in the electrolyte within the pores of the graphite electrode. If compared to the total amount of transition metals in the NMC cathode $\left(157 \mu \mathrm{mol}_{\mathrm{Ni}, \text { total }}, 52 \mu \mathrm{mol}_{\mathrm{Mn} \text {,total }}\right.$, and $52 \mu \mathrm{mol}_{\mathrm{Co}, \text { total }}$; see Experimental section), this corresponds to $0.13 \%_{\mathrm{Ni}(\mathrm{XAS})}, 0.08 \%_{\mathrm{Mn}(\mathrm{XAS})}$, and $0.15 \%_{\mathrm{Co}(\mathrm{XAS})}$ (Table II). These values are within a factor of 2-3 of the values we obtained using ex-situ ICP-OES analysis, for which we obtained $0.25 \%_{\mathrm{Ni}(\mathrm{ICP})}, 0.23 \%_{\mathrm{Mn}(\mathrm{ICP})}$, and $0.27 \%_{\mathrm{Co}(\mathrm{ICP})}$ (Table II), with deviations between two nominally identical measurements being $\leq 0.03 \%$. While we cannot explain the

Table II. Percentage of Ni, Mn, and Co dissolved from the NMC622 electrode (in \% of the total metal content of the corresponding transition metal in NMC622) and deposited on the graphite electrode determined either based on the measured concentrations in Figures 1b-1d (XAS) or by ICP-OES analysis (ICP). The values of the ICP-OES measurements are the average of the results of two different cells with the errors representing the standard deviation between the two measurements.

\begin{tabular}{ccc} 
Deposited metals on graphite & XAS [\%] & ICP-OES [\%] \\
\hline $\mathrm{Ni}$ & 0.13 & $0.25 \pm 0.01$ \\
$\mathrm{Mn}$ & 0.08 & $0.23 \pm 0.03$ \\
$\mathrm{Co}$ & 0.15 & $0.27 \pm 0.01$
\end{tabular}


origin of the differences observed for XAS and ICP, the measured values clearly show that the transition metals are nearly stoichiometrically dissolved. These measured amounts may be further compared with the ones reported by Wandt et al. ${ }^{15}$ using the same procedure with an NMC111-graphite cell, namely $0.17 \%_{\mathrm{Ni}(\mathrm{XAS})}, 0.09 \%_{\mathrm{Mn}(\mathrm{XAS})}$, and $0.26 \%_{\mathrm{Co}(\mathrm{XAS})}$ based on operando XAS and $0.12 \%_{\mathrm{Ni}(\mathrm{ICP})}, 0.17 \%_{\mathrm{Mn}(\mathrm{ICP})}$, and $0.13 \%_{\mathrm{Co} \text { (ICP) }}$ based on ex-situ ICP analysis. The similarity of the amount of dissolved transition metals if referenced to their content in the NMC material for both NMC111 and the Ni-rich NMC622 indicates that there seems to be no preferential dissolution of any of the transition metals during the cycling procedure shown in Figure 1. Thus, when cycling NMC-graphite cells to cell potentials $>4.6 \mathrm{~V}$, the metals dissolve according to their stoichiometry in the NMC material. Consequently, when cycling Ni-rich NMCs, the amount of dissolved $\mathrm{Ni}$-ions in terms of absolute moles is larger compared to $\mathrm{Mn}$ and $\mathrm{Co}$. This is in agreement with the reported nearly stoichiometric dissolution of $\mathrm{Ni}, \mathrm{Mn}$, and $\mathrm{Co}$ by Gallus et al., ${ }^{16}$ and Choi et al. ${ }^{18}$ for NMC111.

The onset of transition metal dissolution in Figures $1 \mathrm{~b}-1 \mathrm{~d}$ is observed at a cell potential of $\sim 4.8 \mathrm{~V}$, which is reasonably close to the observed release of reactive oxygen from the same NMC622 material starting around $4.7 \mathrm{~V} \mathrm{vs.} \mathrm{Li}^{+} / \mathrm{Li}$, as it was shown in recent publications by our group. ${ }^{7,51}$ In recent work, we showed that the reactive oxygen is at least in part singlet oxygen ${ }^{53}$ which reacts with the ethylene carbonate electrolyte solvent to yield $\mathrm{H}_{2} \mathrm{O}_{2} \cdot{ }^{54}$ At potentials above $4 \mathrm{~V}$, the facile electrooxidation of $\mathrm{H}_{2} \mathrm{O}_{2}$ in turn yields protons, which were shown to decompose the $\mathrm{PF}_{6}{ }^{-}$anion to $\mathrm{PF}_{5}$ and $\mathrm{HF}^{55}$ Thus, we hypothesize that the onset of transition metal dissolution is caused by the lattice oxygen release induced HF formation, which subsequently leads to an etching of the NMC cathode causing transition metal dissolution as reported in the literature. ${ }^{16,56,57}$ In contrast, Evertz et al. ${ }^{58}$ recently proposed that it is not the HF which is causing transition metal dissolution but i) impurities within the NMC host lattice, ii) structural changes of NMC particles leading to particle cracking, or iii) by phase transformation from layered to spinel structures. While we cannot estimate the impact of the impurities within the NMC host lattice based on our data, we believe that the effect of particle cracking and phase transformation from layered to spinel structure ultimately goes back to the formation of HF. This is because the phase transformation causes HF formation via the above described reaction cascade and particle cracking sets free new fresh surface area from which oxygen can be released.

Impact of transition metals on the cycle life of NMC622-graphite cells.-To investigate the impact of dissolved transition metals on the cycling stability of NMC622-graphite cells, we chose rather high concentrations of transition metals in the electrolyte in order to accelerate cell aging. The $30 \mathrm{mM}$ and $60 \mathrm{mM}$ transition metal solutions ( $\equiv 2.4 \mu \mathrm{mol}$ and $4.8 \mu \mathrm{mol}$ in the $80 \mu \mathrm{L}$ of added electrolyte) would correspond to a transition metal amount equal to 3-18\% of the transition metals in the NMC622 active material in these cells (at a loading of $16.2 \mathrm{mg}_{\mathrm{NMC}} / \mathrm{cm}^{2}$, an area of $0.785 \mathrm{~cm}^{2}$, and an NMC622 molecular weight of $96.9 \mathrm{~g} / \mathrm{mol}$, the transition metal content is $79 \mu \mathrm{mol}_{\mathrm{Ni}}$ and $26 \mu \mathrm{mol}_{\mathrm{Mn}}$ and $26 \mu \mathrm{mol}_{\mathrm{Co}}$ ). Due to the high concentrations of the intentionally added transition metals, further dissolution occurring from the NMC622 electrode during the 300 cycles in Figure 5 can be neglected for the applied upper cell cutoff voltage of only $4.2 \mathrm{~V}$, since under exactly the same cycling conditions only $0.08 \%(<<3-18 \%)$ of the transition metals were dissolved from an NMC111 electrode. ${ }^{14}$

In the third cycle (first cycle after addition of transition metals, Figure 5), a significant drop in coulombic efficiency and specific capacity was observed for the cells containing transition metals compared to the LP57 cells. In particular, coulombic efficiencies and capacities in the third cycle increase in the order $\mathrm{Mn}<\mathrm{Ni} \approx \mathrm{Co}<\mathrm{LP57}$. During further cycling, the coulombic efficiency for transition metal containing cells increases and after 50-100 cycles approaches very similar values as the ones measured for the LP57 cells (Figure 5). At that point, also the capacity decay per cycle number is very similar for all the cells in Figure 5, indicating that the transition metals are probably covered under newly formed SEI. The lower specific capacities upon addition of transition metals is in agreement with the report by Joshi et al., who also observed a significantly lower capacity when adding a mixture of $\mathrm{Ni}^{2+}, \mathrm{Co}^{2+}$ and $\mathrm{Mn}^{2+}$ in an overall concentration of $30 \mathrm{mM}$ to NMC111-graphite cells. ${ }^{20}$ However, in their study the effect of the single metals cannot be distinguished, since they used an electrolyte containing all three metals. As shown in Figure 5, we observed a clear difference between $\mathrm{Ni}^{2+}$ and $\mathrm{Co}^{2+}$ on the one hand vs. $\mathrm{Mn}^{2+}$ on the other hand; this is consistent with the much more pronounced effect of $\mathrm{Mn}^{2+}$ compared to $\mathrm{Ni}^{2+}$ on $\mathrm{SEI}$ growth/decomposition reported by Solchenbach et al. ${ }^{36}$

In the literature, it was suggested that the deposition of transition metals on graphite anodes causes additional SEI formation leading to loss of active lithium. ${ }^{17,19-24}$ To test if this holds for all three transition metals, we will compare the observed capacity loss of the cells shown in Figure 5 to the lithium content of the NMC622 electrode after cycling determined via the unit cell dimensions (c/a ratio in Figure 6) in analogy to the report by Buchberger et al. ${ }^{14}$ Table III summarizes the capacity loss $\Delta \mathrm{C}_{\text {cycling }}$ (second column) of these cells over the course of the cycles at $1 \mathrm{C}$-rate (cycles 3-300). To this amount we need to add $\Delta \mathrm{C}_{2 \rightarrow 3}$, which is the difference in specific discharge capacity between cycle 2 and cycle 3 , thereby accounting for both the reduced capacities when switching from a $0.1 \mathrm{C}$-rate during formation to the $1 \mathrm{C}$-rate used during the cycle life test as well as the reduced capacity in the third cycle caused by the addition of transition metals. This adds up a total "missing" lithium amount in the NMC electrode after 300 cycles referred to as $\sum_{\text {EC }}$ (fourth column in Table III). Note that the capacity loss due to electrode polarization which occurs when switching from $0.1 \mathrm{C}$ to $1 \mathrm{C}$ cycling is not a real loss of lithium and could be recovered if the cells were cycled at $0.1 \mathrm{C}$.

If all capacity loss during cycling in Figure 5 was exclusively due to loss of active lithium, we would expect that the lithium amount corresponding to $\sum_{\mathrm{EC}}$ would be missing in the NMC electrode after cycling. Therefore, $\sum_{\mathrm{EC}}$ will be compared to the lithium content of the NMC electrodes determined via post-mortem XRD analysis. The c/a ratios of the NMC electrodes after 300 cycles are summarized in the fifth column of Table III. Using the calibration curve shown in Figure $6 \mathrm{~d}$, the missing lithium content $\left(\mathrm{x}\right.$ in $\mathrm{Li}_{1-\mathrm{x}} \mathrm{NMC}$, sixth column in Table III) can be calculated. This value has to be corrected for the irreversible capacity loss observed for the NMC electrode in the first cycle $(x=0.076$, Figure $6 a)$, which in our experiments is slightly larger than the capacity loss due to graphite SEI formation, analogous to the report by Buchberger et al. ${ }^{14}$ By converting $\mathrm{X}_{\mathrm{ICL}-\text { corr. }}$ to specific capacity values in $\mathrm{mAh} / \mathrm{g}_{\mathrm{NMC}}, \sum_{\mathrm{XRD}}$ is obtained. A comparison of $\sum_{\mathrm{EC}}$ and $\sum_{\mathrm{XRD}}$ (last column in Table III) shows that for the LP57 cells as well as for the transition metal containing cells, the values are very similar within an error of $\pm 4 \mathrm{mAh} / \mathrm{g}_{\mathrm{NMC}}$, which we believe, is within the precision of the used techniques. Therefore, the vast majority of the observed specific capacity losses are due to the loss of active lithium, which is in agreement with the report by Vissers et al. ${ }^{59}$ Furthermore, Schwieters et al. showed that $\mathrm{Mn}$ is primarily deposited in the region of the graphite anode close to the separator, in which region also a higher concentration of lithium bound in the SEI was found. ${ }^{60}$

In the following, we will briefly discuss the effect of polarization increase induced by the additional SEI formation, which goes hand in hand with the active lithium loss. By comparing the absolute values of $\overline{\mathrm{V}}_{\text {discharge }}^{\text {anod }}$ in Figure $5 \mathrm{c}$ of the $60 \mathrm{mM}$ Mn cell (green) and the LP57 cell (black), i.e., the cells with worst and best cycling stability, one can observe that the difference is only $\sim 0.1 \mathrm{~V}$ at a $1 \mathrm{C}$-rate. Even if we assigned the total difference in $\overline{\mathrm{V}}_{\text {discharge }}^{\text {anode }}$ to an increase in impedance, the polarization growth would only have a minor contribution; all the more because this assignment is definitely overestimating the polarization effect $\left(\bar{V}_{\text {discharge }}^{\text {anode }}\right.$ is also increased by the evident lithium loss, which is especially large in the $60 \mathrm{mM}$ Mn cells). Additionally, the concentration of $60 \mathrm{mM} \mathrm{Mn}^{2+}$ corresponds to an exceedingly high dissolution of $18 \%$ of the manganese in the NMC active material. In other words, even though additional SEI is formed, the Li-ion resistivity through it has no or at best only a minor influence on the 
Table III. Capacity losses $\Delta \mathrm{C}_{\text {cycling }}$ (second column) of NMC622-graphite cells depicted in Figure 5 after 300 cycles, with the first two cycles conducted at $0.1 \mathrm{C}$-rate and cycle 3-300 at $1 \mathrm{C}$ with or without transition metals added to the electrolyte. $\Delta \mathrm{C}_{2 \rightarrow 3}$ is the change in specific discharge capacity between the second and third cycle accounting for both the higher polarization at higher C-rate and the drop in capacity upon addition of the transition metals. $\sum \mathrm{EC}$ (fourth column) is the sum of $\Delta \mathbf{C}_{\text {cycling }}$ and $\Delta \mathbf{C}_{2 \rightarrow 3}$, indicating the "missing" lithium amount in the NMC electrode based on the electrochemical data. $\sum_{\mathrm{EC}}$ is compared to the capacity losses obtained from XRD analysis $\sum$ XRD of harvested NMC622 electrodes (in the discharged state after 300 cycles) via quantification of the c/a-value (fifth column) by ex situ XRD. Conversion into $x$ in $\mathrm{Li}_{1-\mathrm{x}} \mathrm{NMC} \mathrm{was}$ done using the in-situ XRD calibration curve (Figure 6). By subtracting the lithium ion loss due to the irreversible capacity of the first cycle, $\mathrm{x}_{\mathrm{ICL}}$-corr. is obtained. Conversion of $\mathrm{x}_{\mathrm{ICL}-c o r r}$ into $\mathrm{mAh} / \mathrm{g}$ (using the theoretical capacity of $276.5 \mathrm{mAh} / \mathrm{g}_{\mathrm{NMC}}$ ) yields $\sum$ xrD. The right-most column gives the variance between the electrochemically observed and the XRD-determined capacity loss.

Electrochemical cycling data

Electrolyte $\quad \Delta \mathrm{C}_{\text {cycling }}[\mathrm{mAh} / \mathrm{g}] \quad \Delta \mathrm{C}_{2 \rightarrow 3}[\mathrm{mAh} / \mathrm{g}] \quad \sum_{\mathrm{EC}}[\mathrm{mAh} / \mathrm{g}]$

LP57

$+30 \mathrm{mM} \mathrm{Ni}$

$+30 \mathrm{mM} \mathrm{Mn}$

$+30 \mathrm{mM} \mathrm{Co}$

$+60 \mathrm{mM} \mathrm{Ni}$

$+60 \mathrm{mM} \mathrm{Mn}$

$+60 \mathrm{mM} \mathrm{Co}$

$\begin{array}{ccc}9.4 & 13.0 & 22.4 \\ 17.0 & 16.8 & 33.8 \\ 31.2 & 21.3 & 52.5 \\ 23.3 & 15.0 & 38.3 \\ 15.5 & 21.7 & 37.2 \\ 46.0 & 42.2 & 88.2 \\ 18.8 & 16.0 & 34.8\end{array}$

\begin{tabular}{c}
\hline $\mathrm{c} / \mathrm{a} \quad \mathrm{x}$ \\
5.0045 \\
5.0179 \\
5.0457 \\
5.0254 \\
5.0233 \\
5.1016 \\
5.0264
\end{tabular}

$\mathrm{x}$ in $\mathrm{Li}_{1-\mathrm{x}} \mathrm{NMC}$
0.15
0.19
0.27
0.21
0.21
0.41
0.22

XRD data

cycling stability. This is in agreement with Gilbert et al., who observed only minor changes in the impedance of the graphite electrode in NMC532-graphite cells after 400 cycles, even though they showed substantial transition metal deposition on the graphite anode. ${ }^{21}$

It is important to note that based on the data in Table III, irrespective of which transition metal is added, lithium loss is the main aging mechanism under the used cycling conditions, yet the magnitude is much higher for $\mathrm{Mn}^{2+}$ compared to $\mathrm{Ni}^{2+}$ and $\mathrm{Co}^{2+}$, but for all higher than in pure LP57. The much more detrimental effect of Mn compared to $\mathrm{Ni}$ was also shown in a recent study by Solchenbach et al. ${ }^{36}$

As in the experiments shown in Figure 5 a rather high amount of transition metals were added (corresponding to 3-18\% of the $\mathrm{Ni}$, $\mathrm{Mn}$, and Co in NMC622), we would like to discuss the importance of transition metal dissolution and subsequent deposition on the anode under real battery cycling conditions. Buchberger et al. ${ }^{14}$ and Evertz et al. ${ }^{58}$ showed for NMC111 that for upper cutoff potentials of $\leq 4.3 \mathrm{~V}$ during cycling the amount of dissolved transition metals does not exceed $0.1 \%$. Even though these amounts are low, a slow but continuous dissolution of transition metals over the lifetime of several years of a battery cell may contribute significantly to capacity fading. This is even promoted by the fact that one dissolved transition metal causes the loss of several $\mathrm{Li}^{+}$ions in the anode SEI. For instance, Gilbert et al. ${ }^{24}$ estimated a consumption of $\sim 100$ lithium ions in the SEI per Mn deposited on the anode. Therefore, even small amounts of dissolved transition metals from NMC can have a severe impact on capacity fading. Interestingly, Thompson et al. ${ }^{61}$ recently reported under very harsh cycling conditions of $55^{\circ} \mathrm{C}$ a capacity fading of only $\sim 12 \%$ over $\sim 750$ cycles for single crystal NMC532-graphite cells cycled up to $4.4 \mathrm{~V}$. They also reported only low amounts of $<0.1 \%$ of dissolved transition metals, with hardly any increase after formation. Therefore, it was concluded that transition metal dissolution did not have a significant impact on the cycle life of their cells. Their observations show that the electrolyte and/or the active material can have a significant impact on transition metal dissolution. We believe that there may be three main reasons for their observation: i) the use of single crystal NMC leads to less oxygen release compared to polycrystalline NMC at moderate temperature (as shown by Li et al. ${ }^{62}$ ) and a concomitantly lower extent of HF formation (see discussion above), thereby preventing larger amounts of transition metal dissolution; ii) the use of electrolyte additives by Thompson et al. ${ }^{61}$ may protect the cathode surface by forming a thin film on top of it; and, iii) the electrolyte additives diminish the impact of deposited metals on the anode as was also recently shown by Solchenbach et al. ${ }^{36}$ when comparing the effect of transition metal deposits on an SEI formed with $\mathrm{VC}$ additive.

Proposed mechanism for lithium loss caused by transition metal deposits.-To understand the mechanism behind the lithium loss in
NMC-graphite cells caused by the transition metal deposition, we first want to discuss the observed oxidation states of the transition metal deposits. Based on the reduction potentials of $\mathrm{Ni}, \mathrm{Mn}$, and $\mathrm{Co}$ presented in Figure 3 and the very low voltage of a graphite anode $\left(<0.4 \mathrm{~V} \mathrm{vs} . \mathrm{Li}^{+} / \mathrm{Li}\right)$, the metal ions would be expected to be deposited in their metallic state for all three transition metals. However, as shown in the operando XAS spectra in Figure 2, Ni and Co are deposited on the graphite anode in their + II state, which is in agreement with our previous report using the same operando XAS approach. ${ }^{15}$ For Mn deposition on graphite, very differing results were reported, with oxidation states ranging from $\mathrm{Mn}(0),{ }^{63,64} \mathrm{Mn}^{2+},{ }^{19} \mathrm{Mn}^{3+65-67}$ up to $\mathrm{Mn}^{4+} .{ }^{8}$ Due to the comparably low energy of the Mn K-edge and the low signal intensity causing a rather noisy spectrum, we cannot state whether the deposits are $\mathrm{Mn}^{2+}$ or $\mathrm{Mn}^{3+}$. However, $\mathrm{Mn}(0)$ or $\mathrm{Mn}^{4+}$ in an operating cell in the presence of electrolyte can be ruled out based on our results, consistent with our previous operando XAS studies with NMC111, where manganese was found to be deposited in the $\mathrm{Mn}^{2+}$ state. $^{15}$

Wandt et al. and Delacourt et al. proposed that Mn deposited on graphite undergoes catalytic cycles in which Mn is electrochemically reduced on the graphite anode and subsequently re-oxidized by reducing the electrolyte solvent, thereby causing a constant loss of active lithium. ${ }^{15,68}$ The presence of $\mathrm{Mn}^{2+}$ was observed as long as electrolyte was present, and only changed to $\mathrm{Mn}(0)$ when the electrolyte was removed. ${ }^{15}$ This was rationalized by a much higher rate for the $\mathrm{Mn}(0)$ re-oxidation than the reduction of $\mathrm{Mn}^{2+}$, yielding the oxidized species as the one being observed in presence of electrolyte. ${ }^{15}$ Upon removal of the electrolyte, the catalytic cycle is stopped and the reoxidation of $\mathrm{Mn}(0)$ is being prevented. ${ }^{15}$ Yet, a similar occurrence of $\mathrm{Ni}(0)$ or $\mathrm{Co}(0)$ was not observed upon electrolyte removal. ${ }^{15}$ This is somewhat surprising, as the reduction potentials of $\mathrm{Ni}^{2+}$ and $\mathrm{Co}^{2+}$ are $\sim 1 \mathrm{~V}$ higher than the one of $\mathrm{Mn}^{2+}$ (Figure 3). It was hypothesized that $\mathrm{Ni}$ and $\mathrm{Co}$ might be trapped in the outer SEI in their +2 oxidation state, preventing their reduction to the metallic state. ${ }^{15}$ Using XPS depth profiling, Bar-Tow et al. reported for arsenic deposits on graphite the presence of different oxidation states dependent on their position in the SEI. In particular, $\operatorname{As}(0)$ was found in the inner SEI, while As(III) and As(IV) were found in the outer SEI. ${ }^{69} \mathrm{Un}$ fortunately, such data do not exist for $\mathrm{Ni}$ and $\mathrm{Co}$; however, for $\mathrm{Mn}$, Shkrob et al. showed that it is predominantly deposited in the inner SEI in a lithium carbonate matrix. ${ }^{70}$ Using XPS, Joshi et al. observed the formation of $\mathrm{Li}_{2} \mathrm{CO}_{3}$ in the SEI formed with EC-based electrolyte when $\mathrm{Ni}, \mathrm{Co}$, and $\mathrm{Mn}$ were added simultaneously, while it was absent in electrolyte without added transition metals. ${ }^{20}$ This is in line with previous reports showing that the addition of transition metals leads to a growing fraction of the inorganic components in the SEI. ${ }^{22,64,68}$ Based on these reports and our observations, we hypothesize that the metals are probably initially electrochemically deposited on the 
carbon in their metallic state, which explains their accumulation on the anode, ${ }^{15,68}$ but are subsequently chemically re-oxidized by a reaction with an SEI component, thereby damaging the SEI and forming more of the inorganic components.

The reason why we expect a reaction with the SEI instead of a direct reaction with the electrolyte solvent (which is assumed in the catalytic cycle mechanism mentioned above) is because a direct chemical reaction of transition metals with electrolyte in the absence of an SEI is unlikely. Firstly, because the reduction potentials of the transition metals are higher than the one of the LP57 electrolyte (Figure 3), i.e., the reduction of electrolyte with concurrent oxidation of the metal would be endergonic and, secondly, as shown in Figure 4, a re-oxidation of deposited $\mathrm{Ni}$ on the carbon surface is possible in the absence of an SEI, proving that as long as no SEI is formed, reversible oxidation/reduction of the transition metal is possible. Therefore, the detrimental effect of the transition metals might originate from a chemical decomposition of the SEI components as recently suggested by Leung ${ }^{71}$ and experimentally proven afterwards by Solchenbach et al. ${ }^{36}$ The more negative effect of Mn compared to Ni and Co could be due to a faster reaction with the SEI components or even a different reaction yielding different reaction products, which may cause more damage to the SEI. Using OEMS, Solchenbach et al. ${ }^{36}$ showed that LEDC is decomposed to $\mathrm{Li}_{2} \mathrm{CO}_{3}$ and $\mathrm{C}_{2} \mathrm{H}_{4}$ in the presence of $\mathrm{Mn}$, while it was not observed on the time scale of these measurements (few hours) in the presence of Ni. It is important to note that it is probably the damage to the SEI integrity, namely crack formation during the LEDC decomposition to $\mathrm{Li}_{2} \mathrm{CO}_{3}$ that causes additional irreversible capacity (electrolyte reduction), rather than the simple presence of $\mathrm{Li}_{2} \mathrm{CO}_{3}$ which should give the SEI sufficient passivating properties. This SEI decomposition reaction also explains the $\mathrm{Li}_{2} \mathrm{CO}_{3}$ formation reported by Joshi et al. ${ }^{20}$ and the $\mathrm{Li}_{2} \mathrm{CO}_{3}$ environment around the $\mathrm{Mn}$ deposits reported by Shkrob et al. ${ }^{70}$ Additionally, a chemical reaction with the SEI is also in line with the proposed metathesis reaction of $\mathrm{Mn}^{2+}$ with $\mathrm{Li}^{+}$-containing SEI compounds by Zhan et al. ${ }^{19} \mathrm{~A}$ similar reaction scenario also explains why we did not observe a reoxidation peak of deposited $\mathrm{Ni}$ in the presence of an SEI in Figure 4 because it was already chemically oxidized to $\mathrm{Ni}^{2+}$, which agrees also with the observed $\mathrm{Ni}^{2+}$ in Figure 2, even though according to the reduction potentials presented in Figure 3, metallic states could be expected. Finally, such a chemical reaction pathway would go along with locally destroying the SEI layer, which in consequence leads to additional SEI formation and the observed Li-loss (Table III) causing a faster cell aging (Figure 5).

\section{Conclusions}

In this work we investigated the transition metal dissolution from NMC622 and the deposition of nickel, manganese, and cobalt on the graphite anode using operando X-ray absorption spectroscopy. We showed that at high potentials $\mathrm{Ni}, \mathrm{Mn}$, and Co dissolve nearly stoichiometrically, so that the absolute amounts of $\mathrm{Ni}$ deposited on the graphite anode are highest for the nickel-rich NMC622 active material. By a comparison with the literature we also proved that the total amount of dissolved metals for the used NMC622 electrode is very similar to the one of NMC111.

As in Ni-rich NMCs Ni is the metal which is released at the highest concentration, we compared the detrimental effect of $\mathrm{Ni}, \mathrm{Mn}$, or $\mathrm{Co}$ on NMC622-graphite cells to estimate the significance of every single transition metal on battery cell aging. We demonstrated that the major aging mechanism for all three transition metals is the loss of active lithium, which likely stems from a decomposition of the SEI layer by a chemical reaction of the deposited metals with the SEI. Finally, we showed that the total loss of cycleable lithium is significantly larger when $\mathrm{Mn}$ is deposited on graphite than in the case of $\mathrm{Ni}$ and Co. For the latter two, very similar lithium losses were observed. This shows that replacing commonly used NMC111 cathodes by Ni-rich NMCs like NMC622 not only increases the specific energy of a Li-ion battery, but also that the detrimental effect of metal dissolution and the associated loss of cycleable lithium might be less severe than in the case of Mn-rich NMCs.

\section{Acknowledgment}

The authors thank the BMW Group for the financial support of this work. Umicore is greatly acknowledged for supplying the NMC622 cathode material. We thank Dr. Karin Kleiner for experimental support during the beamtime. R.J. thanks TUM-IAS for their support in the frame of the Rudolf-Diesel Fellowship of Dr. Peter Lamp. F.L. acknowledges the BMBF (Federal Ministry of Education and Research, Germany) for funding within the project "ExZellTUM II" (grant number 03XP0081). R.T., J.W., and M.T. acknowledge financial support by the Bavarian Ministry of Economic Affairs and Media, Energy and Technology under the auspices of the EEBatt project. S.S. thanks BASF SE for funding through its electrochemistry and battery research network. M.T. acknowledges financial support by NOW VIDI, 723.014.010 and the Research Priority Area Sustainable Chemistry of the UvA.

\section{ORCID}

Roland Jung (1) https://orcid.org/0000-0003-1135-7438

Sophie Solchenbach (D) https://orcid.org/0000-0001-6517-8094

\section{References}

1. O. Groeger, H. A. Gasteiger, and J.-P. Suchsland, J. Electrochem. Soc., 162, A2605 (2015).

2. F. T. Wagner, B. Lakshmanan, and M. F. Mathias, J. Phys. Chem. Lett., 1, 2204 (2010).

3. D. Andre, S.-J. Kim, P. Lamp, S. F. Lux, F. Maglia, O. Paschos, and B. Stiaszny, J. Mater. Chem. A, 3, 6709 (2015)

4. K. G. Gallagher, S. Goebel, T. Greszler, M. Mathias, W. Oelerich, D. Eroglu, and V. Srinivasan, Energy Environ. Sci., 7, 1555 (2014).

5. H.-J. Noh, S. Youn, C. S. Yoon, and Y.-K. Sun, J. Power Sources, 233, 121 (2013).

6. W. Liu, P. Oh, X. Liu, M.-J. Lee, W. Cho, S. Chae, Y. Kim, and J. Cho, Angew. Chem., Int. Ed., 54, 4440 (2015)

7. R. Jung, M. Metzger, F. Maglia, C. Stinner, and H. A. Gasteiger, J. Electrochem. Soc., 164, A1361 (2017).

8. L. Yang, M. Takahashi, and B. Wang, Electrochim. Acta, 51, 3228 (2006)

9. T. Inoue and M. Sano, J. Electrochem. Soc., 145, 3704 (1998).

10. A. Du Pasquier, A. Blyr, P. Courjal, D. Larcher, G. Amatucci, B. Gérand, and J. M. Tarascon, J. Electrochem. Soc., 146, 428 (1999).

11. J. Cho and M. M. Thackeray, J. Electrochem. Soc., 146, 3577 (1999).

12. Y. Xia, Y. Zhou, and M. Yoshio, J. Electrochem. Soc., 144, 2593 (1997)

13. D. H. Jang, Y. J. Shin, and S. M. Oh, J. Electrochem. Soc., 143, 2204 (1996).

14. I. Buchberger, S. Seidlmayer, A. Pokharel, M. Piana, J. Hattendorff, P. Kudejova, R. Gilles, and H. A. Gasteiger, J. Electrochem. Soc., 162, A2737 (2015).

15. J. Wandt, A. Freiberg, R. Thomas, Y. Gorlin, A. Siebel, R. Jung, H. A. Gasteiger, and M. Tromp, J. Mater. Chem. A, 4, 18300 (2016).

16. D. R. Gallus, R. Schmitz, R. Wagner, B. Hoffmann, S. Nowak, I. Cekic-Laskovic, R. W. Schmitz, and M. Winter, Electrochim. Acta, 134, 393 (2014).

17. H. Zheng, Q. Sun, G. Liu, X. Song, and V. S. Battaglia, J. Power Sources, 207, 134 (2012).

18. W. Choi and A. Manthiram, J. Electrochem. Soc., 153, A1760 (2006)

19. C. Zhan, J. Lu, A. J. Kropf, T. Wu, A. N. Jansen, Y.-K. Sun, X. Qiu, and K. Amine, Nat. Commun., 4, 3437 (2013).

20. T. Joshi, K. Eom, G. Yushin, and T. F. Fuller, J. Electrochem. Soc., 161, A1915 (2014).

21. J. A. Gilbert, J. Bareño, T. Spila, S. E. Trask, D. J. Miller, B. J. Polzin, A. N. Jansen, and D. P. Abraham, J. Electrochem. Soc., 164, A6054 (2017).

22. H. Tsunekawa, S. Tanimoto, R. Marubayashi, M. Fujita, K. Kifune, and M. Sano, J. Electrochem. Soc., 149, A1326 (2002).

23. N. P. W. Pieczonka, Z. Liu, P. Lu, K. L. Olson, J. Moote, B. R. Powell, and J.-H. Kim, The Journal of Physical Chemistry C, 117, 15947 (2013).

24. J. A. Gilbert, I. A. Shkrob, and D. P. Abraham, J. Electrochem. Soc., 164, A389 (2017).

25. M. Newville, J. Synchrotron Radiat., 8, 322 (2001).

26. B. Ravel and M. Newville, J. Synchrotron Radiat., 12, 537 (2005).

27. Y. Gorlin, A. Siebel, M. Piana, T. Huthwelker, H. Jha, G. Monsch, F. Kraus, H. A. Gasteiger, and M. Tromp, J. Electrochem. Soc., 162, A1146 (2015).

28. S. Meini, N. Tsiouvaras, K. U. Schwenke, M. Piana, H. Beyer, L. Lange, and H. A. Gasteiger, Phys. Chem. Chem. Phys., 15, 11478 (2013).

29. I. Buchberger, $P h D$ Thesis, Electrochemical and structural investigations on lithiumion battery materials and related degradation processes, Technical University Munich, 2016. 
30. M. Metzger, B. Strehle, S. Solchenbach, and H. A. Gasteiger, J. Electrochem. Soc., 163, A798 (2016).

31. B. Zhang, M. Metzger, S. Solchenbach, M. Payne, S. Meini, H. A. Gasteiger, A. Garsuch, and B. L. Lucht, J. Phys. Chem. C, 119, 11337 (2015).

32. M. Pourbaix, Atlas of electrochemical equilibria in aqueous solutions, National Association of Corrosion Engineers, 1974.

33. Y.-K. Han, K. Lee, S. Kang, Y. S. Huh, and H. Lee, Computational Materials Science, 81, 548 (2014).

34. B. Strehle, S. Solchenbach, M. Metzger, K. U. Schwenke, and H. A. Gasteiger, Journal of The Electrochemical Society, 164, A2513 (2017).

35. R. Bernhard, M. Metzger, and H. A. Gasteiger, J. Electrochem. Soc., 162, A1984 (2015).

36. S. Solchenbach, G. Hong, A. Freiberg, R. Jung, and H. A. Gasteiger, J. Electrochem. Soc., 165, A3304 (2018).

37. E. Peled, J. Electrochem. Soc., 126, 2047 (1979).

38. J. Christensen and J. Newman, J. Electrochem. Soc., 152, A818 (2005).

39. E. Peled, D. Bar Tow, A. Merson, A. Gladkich, L. Burstein, and D. Golodnitsky, Journal of Power Sources, 97, 52 (2001).

40. E. Peled and S. Menkin, J. Electrochem. Soc., 164, A1703 (2017).

41. V. Eshkenazi, E. Peled, L. Burstein, and D. Golodnitsky, Solid State Ionics, 170, 83 (2004).

42. S.-H. Kang, D. P. Abraham, W.-S. Yoon, K.-W. Nam, and X.-Q. Yang, Electrochim. Acta, 54, 684 (2008).

43. S.-H. Kang, W.-S. Yoon, K.-W. Nam, X.-Q. Yang, and D. P. Abraham, J. Mater. Sci., 43, 4701 (2008).

44. N. Yabuuchi, Y. Makimura, and T. Ohzuku, J. Electrochem. Soc., 154, A314 (2007).

45. J. Li, L. E. Downie, L. Ma, W. Qiu, and J. R. Dahn, J. Electrochem. Soc., 162, A1401 (2015).

46. Y. Koyama, N. Yabuuchi, I. Tanaka, H. Adachi, and T. Ohzuku, J. Electrochem. Soc., 151, A1545 (2004).

47. W.-S. Yoon, C. P. Grey, M. Balasubramanian, X.-Q. Yang, D. A. Fischer, and J. McBreen, Electrochem. Solid-State Lett., 7, A53 (2004).

48. C. F. Petersburg, Z. Li, N. A. Chernova, M. S. Whittingham, and F. M. Alamgir, J. Mater. Chem., 22, 19993 (2012).

49. M. Sathiya, G. Rousse, K. Ramesha, C. P. Laisa, H. Vezin, M. T. Sougrati, M. L. Doublet, D. Foix, D. Gonbeau, W. Walker, A. S. Prakash, M. Ben Hassine, L. Dupont, and J. M. Tarascon, Nat Mater, 12, 827 (2013).

50. E. McCalla, A. M. Abakumov, M. Saubanere, D. Foix, E. J. Berg, G. Rousse, M.-L. Doublet, D. Gonbeau, P. Novak, G. Van Tendeloo, R. Dominko, and J.-M. Tarascon, Science (Washington, DC, U. S.), 350, 1516 (2015).
51. R. Jung, M. Metzger, F. Maglia, C. Stinner, and H. A. Gasteiger, J. Phys. Chem. Lett., 4820 (2017).

52. R. Jung, P. Strobl, F. Maglia, C. Stinner, and H. A. Gasteiger, J. Electrochem. Soc., 165, A2869 (2018).

53. J. Wandt, A. Freiberg, A. Ogrodnik, and H. A. Gasteiger, Materials Today, 21, 825 (2018).

54. A. T. S. Freiberg, M. K. Roos, J. Wandt, R. de Vivie-Riedle, and H. A. Gasteiger, J. Phys. Chem. A, 122, 8828 (2018).

55. S. Solchenbach, M. Metzger, M. Egawa, H. Beyer, and H. A. Gasteiger, J. Electrochem. Soc., 165, A3022 (2018).

56. J. C. Hunter, Journal of Solid State Chemistry, 39, 142 (1981).

57. D. Aurbach, M. D. Levi, K. Gamulski, B. Markovsky, G. Salitra, E. Levi, U. Heider, L. Heider, and R. Oesten, Journal of Power Sources, 81, 472 (1999).

58. M. Evertz, F. Horsthemke, J. Kasnatscheew, M. Börner, M. Winter, and S. Nowak, J. Power Sources, 329, 364 (2016).

59. D. R. Vissers, Z. Chen, Y. Shao, M. Engelhard, U. Das, P. Redfern, L. A. Curtiss, B. Pan, J. Liu, and K. Amine, ACS Applied Materials \& Interfaces, 8, 14244 (2016).

60. T. Schwieters, M. Evertz, A. Fengler, M. Börner, T. Dagger, Y. Stenzel, P. Harte, M. Winter, and S. Nowak, J. Power Sources, 380, 194 (2018).

61. L. M. Thompson, W. Stone, A. Eldesoky, N. K. Smith, C. R. M. McFarlane, J. S. Kim, M. B. Johnson, R. Petibon, and J. R. Dahn, Journal of The Electrochemical Society, 165, A2732 (2018).

62. J. Li, A. R. Cameron, H. Li, S. Glazier, D. Xiong, M. Chatzidakis, J. Allen, G. A. Botton, and J. R. Dahn, Journal of The Electrochemical Society, 164, A1534 (2017).

63. S. R. Gowda, K. G. Gallagher, J. R. Croy, M. Bettge, M. M. Thackeray, and M. Balasubramanian, Phys. Chem. Chem. Phys., 16, 6898 (2014).

64. X. Xiao, Z. Liu, L. Baggetto, G. M. Veith, K. L. More, and R. R. Unocic, Phys. Chem. Chem. Phys., 16, 10398 (2014).

65. Z. Li, A. D. Pauric, G. R. Goward, T. J. Fuller, J. M. Ziegelbauer, M. P. Balogh, and I. C. Halalay, J. Power Sources, 272, 1134 (2014).

66. S. Komaba, T. Itabashi, T. Ohtsuka, H. Groult, N. Kumagai, B. Kaplan, and H. Yashiro, J. Electrochem. Soc., 152, A937 (2005).

67. A. Banerjee, Y. Shilina, B. Ziv, J. M. Ziegelbauer, S. Luski, D. Aurbach, and I. C. Halalay, JACS, 139, 1738 (2017).

68. C. Delacourt, A. Kwong, X. Liu, R. Qiao, W. L. Yang, P. Lu, S. J. Harris, and V. Srinivasan, J. Electrochem. Soc., 160, A1099 (2013).

69. D. Bar-Tow, E. Peled, and L. Burstein, J. Electrochem. Soc., 146, 824 (1999).

70. I. A. Shkrob, A. J. Kropf, T. W. Marin, Y. Li, O. G. Poluektov, J. Niklas, and D. P. Abraham, J. Phys. Chem. C, 118, 24335 (2014).

71. K. Leung, Chemistry of Materials, 29, 2550 (2017). 